\title{
Perturbation of the two-component signal transduction system, BprRS, results in attenuated virulence and motility defects in Burkholderia pseudomallei
}

Natalie R. Lazar Adler ${ }^{1,6+}$, Elizabeth M. Allwood ${ }^{1+}$, Deanna Deveson Lucas ${ }^{1,2}$, Paul Harrison ${ }^{3}$, Stephen Watts ${ }^{1}$, Alexandra Dimitropoulos ${ }^{2,4}$, Puthayalai Treerat ${ }^{1,7}$, Priyangi Alwis ${ }^{1,8}$, Rodney J. Devenish ${ }^{2,4}$, Mark Prescott ${ }^{2,4}$, Brenda Govan ${ }^{5}$, Ben Adler ${ }^{1,2}$, Marina Harper ${ }^{1,2}$ and John D. Boyce ${ }^{1,2^{*}}$

\begin{abstract}
Background: Burkholderia pseudomallei is the causative agent of melioidosis, a severe invasive disease of humans and animals. Initial screening of a B. pseudomallei signature-tagged mutagenesis library identified an attenuated mutant with a transposon insertion in a gene encoding the sensor component of an uncharacterised two-component signal transduction system (TCSTS), which we designated BprRS.

Results: Single gene inactivation of either the response regulator gene (bprR) or the sensor histidine kinase gene (bprS) resulted in mutants with reduced swarming motility and reduced virulence in mice. However, a bprRS double mutant was not attenuated for virulence and displayed wild-type levels of motility. The transcriptomes of the bprS, bprR and bprRS mutants were compared with the transcriptome of the parent strain K96243. Inactivation of the entire BprRS TCSTS (bprRS double mutant) resulted in altered expression of only nine genes, including both bprR and bprS, five phage-related genes and bpss0686, encoding a putative 5, 10-methylene tetrahydromethanopterin reductase involved in one carbon metabolism. In contrast, the transcriptomes of each of the bprR and bprS single gene mutants revealed more than 70 differentially expressed genes common to both mutants, including regulatory genes and those required for flagella assembly and for the biosynthesis of the cytotoxic polyketide, malleilactone.

Conclusions: Inactivation of the entire BprRS TCSTS did not alter virulence or motility and very few genes were differentially expressed indicating that the definitive BprRS regulon is relatively small. However, loss of a single component, either the sensor histidine kinase BprS or its cognate response regulator BprR, resulted in significant transcriptomic and phenotypic differences from the wild-type strain. We hypothesize that the dramatically altered phenotypes of these single mutants are the result of cross-regulation with one or more other TCSTSs and concomitant dysregulation of other key regulatory genes.
\end{abstract}

Keywords: Burkholderia pseudomallei, Two-component signal transduction, Transcriptomics, Flagella, Virulence

\footnotetext{
* Correspondence: john.boyce@monash.edu

Joint senior authors: Marina Harper and John D. Boyce

${ }^{\dagger}$ Equal contributors

'Department of Microbiology, Monash University, 19 Innovation Walk,

Clayton, Victoria 3800, Australia

${ }^{2}$ Infection and Immunity Program, Monash Biomedicine Discovery Institute,

Monash University, Victoria, Australia

Full list of author information is available at the end of the article
}

2016 Lazar Adler et al. Open Access This article is distributed under the terms of the Creative Commons Attribution 4.0 International License (http://creativecommons.org/licenses/by/4.0/), which permits unrestricted use, distribution, and reproduction in any medium, provided you give appropriate credit to the original author(s) and the source, provide a link to the Creative Commons license, and indicate if changes were made. The Creative Commons Public Domain Dedication waiver (http://creativecommons.org/publicdomain/zero/1.0/) applies to the data made available in this article, unless otherwise stated. 


\section{Background}

Burkholderia pseudomallei is a highly pathogenic Gramnegative organism and the causative agent of melioidosis, a potentially fatal infectious disease of humans and animals. The bacterium is endemic to tropical regions including South East Asia and Northern Australia; mortality rates resulting from melioidosis remain extremely high, with up to $42 \%$ mortality in the Northeastern region of Thailand and $14 \%$ mortality in Australia's Northern Territory [1, 2]. Importantly, a $90 \%$ mortality rate is associated with septic shock [3]. In Northern Australia, melioidosis accounts for $32 \%$ of communityacquired bacteraemic pneumonia and $6 \%$ of all bacteraemias [4], while in the Northeastern region of Thailand, the disease accounts for $20 \%$ of all community-acquired septicaemias [5] and is the third most common cause of death from an infectious disease [2]. The complex clinical spectrum of melioidosis, the potentially rapid progression of disease and the fact that B. pseudomallei is innately resistant to a wide range of antimicrobial agents [6-8] makes treatment of this disease difficult.

For B. pseudomallei and most other opportunistic pathogens, the ability to sense external signals is critical for the transition from their environmental niche into the eukaryotic host, as well as for survival within specific niches within the host. Prokaryotic two-component signal transduction systems (TCSTS) constitute a critical set of regulators which act to sense environmental signals and respond by altering gene expression [9-11]. TCSTS generally consist of a membrane-bound sensor kinase (SK) and a cytosolic DNA-binding response regulator (RR) [11]. The SK protein senses extracellular stimuli and responds through the autophosphorylation of a specific histidine residue. This phosphoryl group is then transferred to an aspartate residue on the cytoplasmic $\mathrm{RR}$ leading to a conformational change that activates the $R R$, resulting in the altered expression of a specific set of genes [12]. TCSTS components are promising drug targets as these systems are not present in mammalian cells and inhibitors that target TCSTSs are likely to function in a manner distinct from existing antimicrobial agents, thereby providing an alternative treatment for multidrug resistant bacteria [13]. Moreover, many TCSTS regulate expression of virulence genes and therefore drugs that target TCSTS could reduce virulence without affecting bacterial viability and thus reduce the development of antimicrobial resistance during treatment regimens [14].

The genome of B. pseudomallei strain K96243 encodes more than 60 TCSTS [15] but only a few have been characterized including BPSL2024-5, VirAG, MrgRS and IrlRS. The IrlRS system is involved in the regulation of B. pseudomallei invasion of epithelial cells as well as heavy metal resistance. However, an irlR mutant was not attenuated for virulence in the C57BL/6 mouse, infant diabetic rat and Syrian hamster models [16, 17]. The MrgRS system responds to temperature, with increased expression of $m r g R$ and $m r g S$ observed during growth at $37{ }^{\circ} \mathrm{C}$ compared to $25{ }^{\circ} \mathrm{C}$. This system may be involved in pathogenesis, but its role in virulence has not been specifically tested [18]. The VirAG system regulates the expression of the type VI secretion system cluster 1 (T6SS-1) during growth within macrophages. Both a virG mutant and a T6SS-1 mutant were attenuated for virulence [19]. The gene bpsl2025, encoding the SK of a TCSTS, was first identified in an in vivo hamster infection microarray study and a directed bpsl2025 mutant was significantly attenuated in the hamster model $(\geq 3$ $\log$ increase in $\mathrm{ID}_{50}$ ) [20].

Here we characterise a TCSTS in B. pseudomallei that we have named BprRS. Inactivation of the entire BprRS system via inactivation of both genes had no effect on virulence or motility and RNA expression analysis of the double bprRS mutant revealed few changes in gene expression. However, inactivation of only one component (either $\operatorname{bpr} R$ or $b p r S$ ) led to an attenuated phenotype in both virulence and motility. High-throughput RNA sequencing (RNA-seq) comparing the transcriptomes of the bprS and bprR mutants with the parent strain of $B$. pseudomallei revealed a large number of expression changes in genes required for chemotaxis, flagella biosynthesis and production of malleilactone. Furthermore, many transcriptional regulators were also differentially expressed in the single gene mutant strains. We propose that the altered phenotypes displayed by the bprR and bprS single mutants are due to the orphaned sensor or the orphaned response regulator (respectively) engaging in cross-talk interactions with one or more of the other B. pseudomallei TCSTS.

\section{Results \\ Identification of an attenuated B. pseudomallei bprS (bpss0687) signature-tagged transposon mutant}

A signature-tagged library of 336 B. pseudomallei K96243 mutants was constructed and screened for reduced in vivo growth in the acute (BALB/c) mouse melioidosis model. Mutants displaying reduced hybridisation in the output pools were tested individually for an in vivo growth defect by competitive growth assays. Five mutants were identified that displayed a statistically significant in vivo growth defect $(P<0.001)$. Four of the attenuated mutants contained transposon insertions within genes required for the biosynthesis of 1,3-linked 2-O-acetyl-6-deoxy- $\beta$-D-manno-heptopyranose capsular polysaccharide (three in $w z m 2$, one in $w c b Q$ ). This locus has previously been shown to be important for $B$. pseudomallei virulence [21, 22]. The fifth attenuated mutant contained a Tn5 insertion within bpss0687 (112 bp from 
the 3 ' end) and this mutant was designated bprS:: $\operatorname{Tn} 5$ (Fig. 1a). The presence of a single transposon insertion in this mutant was confirmed by Southern blot analysis (data not shown). The $\mathrm{ID}_{50}$ of the B. pseudomallei parent strain K96243 and the bprS::Tn5 mutant was determined in groups of five BALB/c mice following inoculation via the intranasal (i.n.) or intraperitoneal (i.p.) routes of infection. For the i.n. route of infection, the $\mathrm{ID}_{50}$ of the bprS::Tn5 mutant was $>1.3 \times 10^{7} \mathrm{CFU}$ while the parent strain K96243 was $<1.2 \times 10^{4} \mathrm{CFU}$. For the i.p. route of infection, the $\mathrm{ID}_{50}$ of the bprS::Tn5 mutant was $>1.6 \times 10^{4} \mathrm{CFU}$ compared with $<1.2 \times 10^{3} \mathrm{CFU}$ for the parent strain K96243. Therefore, the bprS::Tn5 mutant was attenuated for virulence via both infection routes in BALB/c mice. Importantly, the bprS::Tn5 mutant displayed normal in vitro growth in both rich medium (2YT) and minimal medium (M9) indicating that the attenuated phenotype was not due to a general growth defect (data not shown).

Bioinformatic analysis of BPSS0687 revealed that the predicted protein sequence displayed significant amino acid identity to a number of characterised histidine kinases, including QseC from Pseudomonas spp. (92\% coverage, $39 \%$ identity). Several conserved amino acid domains were identified within the predicted SK, including a catalytic histidine kinase-like ATPase, C-terminal domain (HATPase_c), a histidine kinase A domain (HisKA), a HAMP (histidine kinases, adenylyl cyclases, methyl-accepting chemotaxis proteins, and phosphatases) signal transduction domain and two transmembrane regions flanking the predicted stimulus-specific region (Fig. 1a). Located immediately upstream of the histidine kinase gene was a gene encoding a protein with receiver and effector domains typical of a RR (bpss0688). RT-PCR using primers that spanned the two genes indicated that bpss0687 and bpss0688 were co-transcribed (data not shown). Together these data indicate that bpss0687 and bpss0688 encode a cognate TCSTS pair named BprRS.

\section{Generation of directed bprS, bprR and bprRS mutants and associated virulence studies}

To confirm that inactivation of $b p r S$ led to an attenuated phenotype, a directed bprS mutant was constructed using double-crossover insertional mutagenesis (Fig. 1a). We first compared the growth of the parent strain K96243 and the mutant in BALB/c mice using competitive growth assays. The bprS mutant displayed normal in vitro growth (data not shown) but the in vivo competitive index of the bprS mutant was $0.094 \pm 0.08$, indicative of an approximately 10-fold reduced growth rate in vivo compared to the parent strain. The attenuated phenotype was then confirmed using virulence trials in BALB/ c mice (Fig. 2). Mice infected with the parent strain K96243 displayed signs of illness by $28-50$ h (days 2-3) and eight of the nine mice were euthanized by $190 \mathrm{~h}$ (day 8) after infection. In contrast, the survival rate in the group infected with the bprS mutant was significantly increased (Fisher's exact test; $P=0.015$ ), with only two mice developing late stage signs of infection and required euthanasia after $190 \mathrm{~h}$.

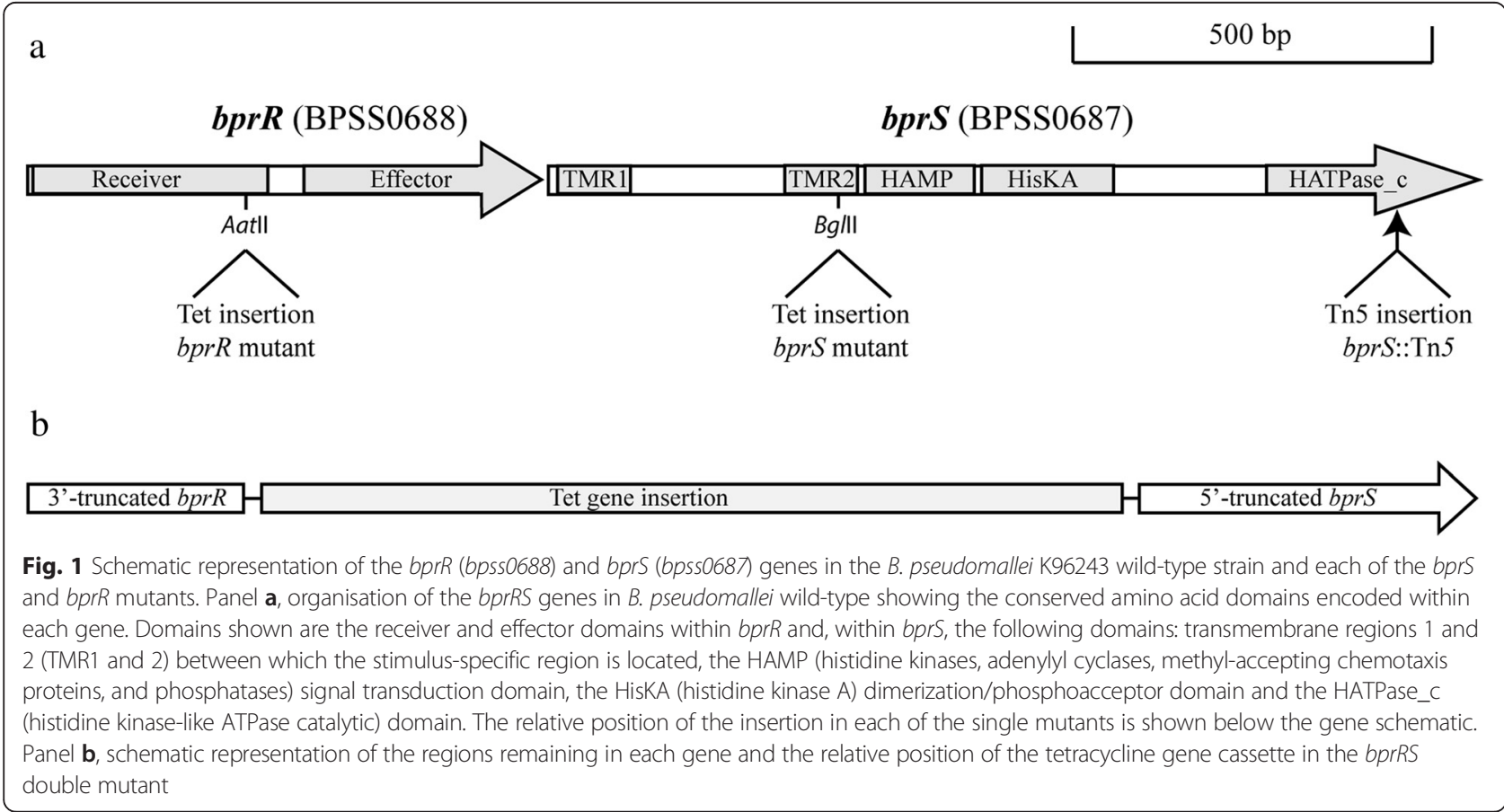




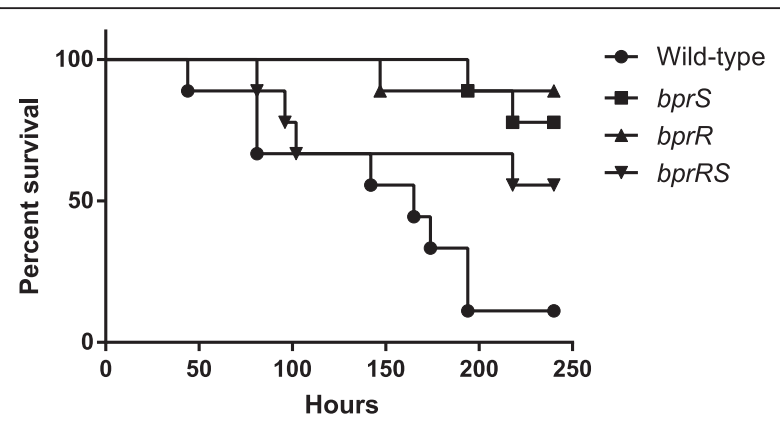

Fig. 2 Kaplan-Meier survival curves for groups of mice infected intranasally with the B. pseudomallei wild-type or the bprs, bprR or bprRS mutant strains. Mice were infected with the following doses; wild-type strain, $6 \times 10^{4} \mathrm{CFU}$; bprs mutant, $8 \times 10^{4} \mathrm{CFU}$, bprR mutant, $3 \times 10^{4}$ CFU, bprRS mutant $9 \times 10^{4} \mathrm{CFU}$

To further characterise the BprRS TCSTS, a directed bprR mutant (Fig. 1a) and a bprRS double mutant (Fig. 1b) were also constructed by double-crossover insertional mutagenesis. The $\operatorname{bpr} R$ mutant was also highly attenuated for virulence $(P=0.003)$ with only a single mouse showing late-stage disease signs at $150 \mathrm{~h}$ (day 6) (Fig. 2). In contrast, the bprRS mutant was not attenuated for virulence as determined by numbers of surviving mice (Fisher's exact test; $P=0.13$ ) or time to euthanasia (Log-rank Mantel-Cox test; $P=0.062$ ) (Fig. 2). These data clearly show that separate inactivation of BprRS TCSTS SK or the RR resulted in decreased virulence, but inactivation of both genes in the BprRS TCSTS system did not.

\section{Transcriptomic analyses of the bprRS double mutant}

TCSTS are critical regulators of bacterial gene expression. To understand why the bprRS mutant was not attenuated for virulence, while the single bprR and bprS mutants were, we analysed the transcriptomes of all three mutant strains and the wild-type strain. Firstly, to identify the genes controlled by the BprRS system we compared the transcriptomes of the bprRS double mutant and the parent strain, K96243. In total, only nine genes were differentially expressed (five with increased and four with decreased expression) in the $\operatorname{bpr} R S$ double mutant (Table 1). Both the truncated bprR and bprS gene fragments showed increased expression, suggesting that the BprRS TCSTS likely regulates its own expression. Two genes, bpss0686 and bpss0686a, located immediately upstream of the bprRS TCSTS genes but transcribed from the other strand, showed increased expression in the bprRS double mutant (Table 1); these genes were also identified as differentially expressed in the bprS single mutant (Table 2). Bioinformatic analyses of bpss0686a revealed no additional information on the open reading frame and analysis of the RNA-seq data revealed that only a single sequence read of the 13 million sequence reads generated from the parent strain (K96243) matched this region, indicating that bpss0686a may not encode a functional protein, or it is not expressed under the conditions used for bacterial growth. Bioinformatic analysis of bpss0686 revealed that it encoded a putative enzyme belonging to the flavinutilizing monoxygenase super family and the nitrilotriacetate monoxgenase sub-family. Moreover, the encoded protein had $65 \%$ identity (96\% coverage) to the 5, 10methylene tetrahydromethanopterin reductase in Methylobacterium extorquens that is required for one carbon metabolism [23]. Five phage-associated genes were also differentially expressed in the bprRS double mutant; four of these showed decreased expression and one, encoding a phage membrane protein (bpss1087), showed increased expression. Three of the phage genes, bpss1087 and bpss1066 (encoding a predicted phage terminase/endonuclease subunits), and bpss1072 (encoding a protein of

Table 1 Genes with differential expression in the bprRS double mutant compared to expression in the wild-type parent strain

\begin{tabular}{|c|c|c|c|}
\hline Locus tag & Gene product/description & bprRS mutant Expression $\left(\log _{2}\right)$ & FDR \\
\hline \multicolumn{4}{|c|}{ Increased expression in bprRS double mutant relative to wild-type expression } \\
\hline BPSS0686 & putative 5, 10-methylenetetrahydro-methanopterin reductase & 3.36 & 3.21E-07 \\
\hline BPSS0686a & protein of unknown function & 5.63 & 7.35E-05 \\
\hline BPSS0687 & BprS-sensor kinase protein & 4.34 & 1.67E-07 \\
\hline BPSS0688 & BprR-response regulator protein & 2.07 & $1.31 \mathrm{E}-05$ \\
\hline BPSS1087 & phage membrane protein & 1.13 & $3.41 \mathrm{E}-03$ \\
\hline \multicolumn{4}{|c|}{ Decreased expression in bprRS double mutant relative to wild-type expression } \\
\hline BPSL0145 & protein of unknown function with ATPase domain, putative phage-encoded & -5.17 & 1.17E-04 \\
\hline BPSL0146 & membrane protein & -3.48 & $9.28 \mathrm{E}-06$ \\
\hline BPSS1066 & phage terminase, endonuclease subunit & -3.62 & 2.86E-03 \\
\hline BPSS1072 & phage-acquired protein & -4.89 & $9.28 \mathrm{E}-06$ \\
\hline
\end{tabular}

Genes were identified as differentially expressed if they showed $>2$-fold expression change $\left(\log _{2}>1.0\right.$ or $\log _{2}<-1.0$ ) compared to the wild-type strain with a False Discovery Rate (FDR) of $<0.01$ 
Table 2 Genes with increased expression in either the bprR and/or bprS single mutants

\begin{tabular}{|c|c|c|c|c|c|c|}
\hline Locus tag & $\begin{array}{l}\text { Gene } \\
\text { name }\end{array}$ & Description & $\begin{array}{l}\text { bprS mutant } \\
\text { Expression }\left(\log _{2}\right)\end{array}$ & $\begin{array}{l}\text { bprS } \\
\text { mutant FDR }\end{array}$ & $\begin{array}{l}\text { bprR mutant } \\
\text { Expression }\left(\log _{2}\right)\end{array}$ & $\begin{array}{l}\text { bprR } \\
\text { mutant FDR }\end{array}$ \\
\hline BPSL0026 & flil & flagellar basal body-associated protein FliL & 2.09 & $8.28 \mathrm{E}-03$ & $1.82 \#$ & $1.52 \mathrm{E}-02$ \\
\hline BPSL0028 & fliN & flagellar motor switch protein & 2.25 & $5.34 \mathrm{E}-03$ & 1.94 & $9.47 \mathrm{E}-03$ \\
\hline BPSL0031 & fliQ & flagellar biosynthesis protein & 2.15 & 5.34E-03 & 1.93\# & $1.08 \mathrm{E}-02$ \\
\hline BPSL0067 & & protein of unknown function & 2.54 & $2.16 \mathrm{E}-05$ & 2.30 & $2.20 \mathrm{E}-05$ \\
\hline BPSL0068 & & putative lipoprotein & 2.46 & $2.16 \mathrm{E}-05$ & 2.30 & 2.11E-05 \\
\hline BPSL0069 & & putative anti-sigma factor & 1.02 & $4.78 \mathrm{E}-03$ & 0.89 & 1.09E-02 \\
\hline BPSL0071 & & putative catalase & 1.31 & $4.26 \mathrm{E}-03$ & 1.47 & $2.44 \mathrm{E}-03$ \\
\hline BPSL0225 & & putative flagellar hook-length control protein & 1.76 & $1.24 \mathrm{E}-03$ & 1.24 & $6.62 \mathrm{E}-03$ \\
\hline BPSL0226 & flij & flagellar fliJ protein & 1.87 & $1.75 \mathrm{E}-03$ & 1.34\# & 1.09E-02 \\
\hline BPSL0227 & flil & flagellum-specific ATP synthase & 1.94 & 5.34E-03 & 1.54\# & $1.32 \mathrm{E}-02$ \\
\hline BPSL0228 & $\mathrm{fliH}$ & flagellar assembly protein $\mathrm{H}$ & 2.04 & 8.43E-03 & 1.69\# & 1.69E-02 \\
\hline BPSL0230 & fliF & flagellar MS-ring protein & 2.14 & $8.20 \mathrm{E}-03$ & 1.75\# & $1.64 \mathrm{E}-02$ \\
\hline BPSL0231 & fliE & flagellar hook-basal body complex protein & 1.81 & 8.84E-03 & 1.39\# & $2.52 \mathrm{E}-02$ \\
\hline BPSL0269 & $f \lg A$ & flagellar basal body P-ring biosynthesis protein FlgA & 2.09 & $2.38 \mathrm{E}-03$ & 1.58\# & $1.08 \mathrm{E}-02$ \\
\hline BPSL0271 & $\mathrm{flgC}$ & flagellar basal body rod protein FlgC & 2.20 & $6.66 \mathrm{E}-03$ & 1.75\# & $1.52 \mathrm{E}-02$ \\
\hline BPSL0272 & $f l g D$ & flagellar basal body rod modification protein & 2.12 & 7.33E-03 & $1.76 \#$ & $1.43 \mathrm{E}-02$ \\
\hline BPSL0273 & $f l g E$ & flagellar hook protein FlgE & 1.88 & $3.02 \mathrm{E}-03$ & 1.39\# & $1.22 \mathrm{E}-02$ \\
\hline BPSL0274 & $f l g F$ & flagellar basal body rod protein FlgF & 1.79 & $4.69 \mathrm{E}-03$ & 1.29\# & $1.66 \mathrm{E}-02$ \\
\hline BPSL0275 & $f l g G$ & flagellar basal body rod protein FlgG & 1.92 & $5.66 \mathrm{E}-03$ & 1.43\# & $1.64 \mathrm{E}-02$ \\
\hline BPSL0276 & $\mathrm{flgH}$ & flagellar basal body L-ring protein & 1.88 & $2.96 \mathrm{E}-03$ & 1.44\# & $1.03 \mathrm{E}-02$ \\
\hline BPSL0278 & flg & flagellar rod assembly protein/muramidase Flg」 & 1.83 & 4.51E-03 & $1.27 \#$ & $1.87 \mathrm{E}-02$ \\
\hline BPSL0403 & & mce related protein & 1.19 & $1.26 \mathrm{E}-03$ & 1.22 & 7.78E-04 \\
\hline BPSL0812 & bpeR & TetR family regulatory protein & 1.09 & 7.33E-03 & 1.08 & $8.20 \mathrm{E}-03$ \\
\hline BPSL0814 & bpeA & $\begin{array}{l}\text { RND family acriflavine resistance protein A } \\
\text { precursor }\end{array}$ & 1.65 & $2.23 \mathrm{E}-03$ & 1.56 & $2.22 \mathrm{E}-03$ \\
\hline BPSL0815 & bpeB & RND family acriflavine resistance protein & 1.84 & 7.63E-03 & 1.79 & $7.22 \mathrm{E}-03$ \\
\hline BPSL1053 & & putative lipoprotein & 0.48 & $3.05 \mathrm{E}-01$ & 1.50 & $5.74 \mathrm{E}-03$ \\
\hline BPSL1112 & & putative lipoprotein & 1.54 & $1.55 \mathrm{E}-03$ & 1.24 & $6.71 \mathrm{E}-03$ \\
\hline BPSL1184 & & putative sugar-related transport, membrane protein & 1.01 & $6.70 \mathrm{E}-03$ & 0.88 & $1.37 \mathrm{E}-02$ \\
\hline BPSL1185 & & protein of unknown function & 3.95 & $3.83 \mathrm{E}-05$ & 4.04 & $2.11 \mathrm{E}-05$ \\
\hline BPSL1202 & & putative transport-related membrane protein & 0.61 & $8.41 \mathrm{E}-02$ & 1.93 & $2.32 \mathrm{E}-04$ \\
\hline BPSL1203 & & putative carbonic anhydrase & 0.63 & $6.17 \mathrm{E}-02$ & 2.03 & $9.28 \mathrm{E}-05$ \\
\hline BPSL1254 & & protein of unknown function & 1.59 & $4.26 \mathrm{E}-03$ & 1.75 & $2.10 \mathrm{E}-03$ \\
\hline BPSL1289 & osmB & osmotically inducible lipoprotein B precursor & 0.72 & 3.89E-02 & 1.66 & $2.80 \mathrm{E}-04$ \\
\hline BPSL1387 & & protein of unknown function & 1.09 & $1.34 \mathrm{E}-03$ & 0.77 & $8.20 \mathrm{E}-03$ \\
\hline BPSL1563 & & $\begin{array}{l}\text { putative membrane protein of unknown } \\
\text { function }\end{array}$ & 1.22 & 5.17E-04 & 1.68 & 4.16E-05 \\
\hline BPSL1564 & & putative transcriptional regulatory protein & 0.50 & 1.17E-01 & 1.37 & $9.39 \mathrm{E}-04$ \\
\hline BPSL1598 & & putative transport-related, membrane protein & 0.28 & $3.17 \mathrm{E}-01$ & 1.59 & $1.66 \mathrm{E}-04$ \\
\hline BPSL1829 & & putative methyl-accepting chemotaxis protein & 1.98 & $4.26 \mathrm{E}-03$ & 1.34\# & $1.89 \mathrm{E}-02$ \\
\hline BPSL1872 & & putative N-acetylmuramoyl-L-alanine amidase & $1.07 \#$ & $3.99 \mathrm{E}-02$ & 1.47 & 9.64E-03 \\
\hline BPSL1931 & & protein of unknown function & 0.83 & $2.35 \mathrm{E}-02$ & 1.01 & $9.10 \mathrm{E}-03$ \\
\hline BPSL2011 & & putative osmosis-related lipoprotein & -0.35 & $2.54 \mathrm{E}-01$ & 1.08 & $2.78 \mathrm{E}-03$ \\
\hline BPSL2016 & & protein of unknown function & 0.78 & $5.21 \mathrm{E}-02$ & 1.30 & $5.35 \mathrm{E}-03$ \\
\hline
\end{tabular}


Table 2 Genes with increased expression in either the bprR and/or bprS single mutants (Continued)

\begin{tabular}{|c|c|c|c|c|c|c|}
\hline BPSL2017 & & di-haem cytochrome c peroxidase & 0.67 & 1.09E-01 & 1.38 & 5.35E-03 \\
\hline BPSL2193 & & protein of unknown function & 0.90 & $7.52 \mathrm{E}-03$ & 1.12 & 2.10E-03 \\
\hline BPSL2282 & & protein of unknown function & 0.62 & $6.86 \mathrm{E}-02$ & 1.97 & $1.20 \mathrm{E}-04$ \\
\hline BPSL2396 & & protein of unknown function & 1.27 & 7.30E-03 & 1.30 & $5.74 \mathrm{E}-03$ \\
\hline BPSL2397 & & protein of unknown function & 1.46 & $2.48 \mathrm{E}-03$ & 1.25 & $5.30 \mathrm{E}-03$ \\
\hline BPSL2398 & & protein of unknown function & 1.12\# & 1.09E-02 & 1.18 & 7.39E-03 \\
\hline BPSL2399 & & putative glycosyltransferase & 1.36 & $1.55 \mathrm{E}-03$ & 1.19 & $2.72 \mathrm{E}-03$ \\
\hline BPSL2409 & & ABC transporter ATP binding protein & 0.85 & $2.82 \mathrm{E}-02$ & 1.09 & 8.00E-03 \\
\hline BPSL2466 & & protein of unknown function & 0.76 & $1.43 \mathrm{E}-02$ & 2.03 & $2.30 \mathrm{E}-05$ \\
\hline BPSL2482 & & peptidase & 1.25 & $2.38 \mathrm{E}-03$ & 1.32 & $1.27 \mathrm{E}-03$ \\
\hline BPSL2483 & & ribosome-associated GTPase & 0.97 & $5.86 \mathrm{E}-03$ & 1.01 & 4.35E-03 \\
\hline BPSL3254B & & protein of unknown function & 1.63 & $1.22 \mathrm{E}-03$ & 1.94 & $2.75 \mathrm{E}-04$ \\
\hline BPSL3291 & fliA & flagellar biosynthesis sigma factor & 1.86 & $2.45 \mathrm{E}-03$ & 1.50 & $6.41 \mathrm{E}-03$ \\
\hline BPSL3292 & flhG & flagellar biosynthesis protein FlhG & 2.21 & $3.79 \mathrm{E}-03$ & 1.74\# & $1.08 \mathrm{E}-02$ \\
\hline BPSL3293 & flhF & flagellar biosynthesis regulator FlhF & 2.23 & $1.83 \mathrm{E}-03$ & 1.75 & $5.35 \mathrm{E}-03$ \\
\hline BPSL3294 & flhA & flagellar biosynthesis protein FlhA & 2.09 & 7.89E-03 & 1.67\# & 1.66E-02 \\
\hline BPSL3323 & & putative transferase & 1.55 & 8.43E-03 & 1.13\# & $2.51 \mathrm{E}-02$ \\
\hline BPSL3324 & & putative keto/oxo acyl-ACP synthase & 1.51 & 7.17E-03 & 0.98 & $3.22 \mathrm{E}-02$ \\
\hline BPSL3326 & & putative keto/oxo acyl-ACP synthase & 1.78 & 8.43E-03 & 1.39\# & 1.99E-02 \\
\hline BPSL3327 & & putative short chain dehydrogenase & 1.74 & $3.62 \mathrm{E}-03$ & 1.26\# & $1.52 \mathrm{E}-02$ \\
\hline BPSL3329 & & Rieske (2Fe-2S) domain-containing protein & 1.31 & 7.21E-03 & 0.95 & 2.29E-02 \\
\hline BPSS0215 & tar & methyl-accepting chemotaxis protein & 1.70 & $6.71 \mathrm{E}-03$ & 1.35\# & $1.58 \mathrm{E}-02$ \\
\hline BPSS0216 & & putative membrane protein of unknown function & 1.12 & 4.45E-03 & 0.82 & $1.97 \mathrm{E}-02$ \\
\hline BPSS0223 & & protein of unknown function & 0.82 & $8.44 \mathrm{E}-03$ & 1.44 & $2.34 \mathrm{E}-04$ \\
\hline BPSS0236 & ItaE & L-allo-threonine aldolase & 0.96 & 2.09E-02 & 1.20 & $6.20 \mathrm{E}-03$ \\
\hline BPSS0264 & & protein of unknown function & 1.02\# & $2.56 \mathrm{E}-02$ & 1.36 & $6.20 \mathrm{E}-03$ \\
\hline BPSS0298 & & transport related membrane protein & 1.60 & $1.36 \mathrm{E}-03$ & 1.07\# & 1.37E-02 \\
\hline BPSS0299 & malM & fatty-acid CoA ligase & 2.20 & 8.23E-03 & 1.63\# & $2.27 \mathrm{E}-02$ \\
\hline BPSS0300 & mall & malonyl CoA-acyl carrier protein & 2.29 & $2.38 \mathrm{E}-03$ & 1.60\# & 1.17E-02 \\
\hline BPSS0301 & malK & protein of unknown function & 2.24 & $1.91 \mathrm{E}-03$ & 1.60 & $9.10 \mathrm{E}-03$ \\
\hline BPSS0302 & mals & fatty acid biosynthesis-related CoA ligase & 2.30 & $2.96 \mathrm{E}-03$ & 1.66\# & $1.29 \mathrm{E}-02$ \\
\hline BPSS0303 & mall & diaminopimelate decarboxylase & 2.39 & 8.17E-04 & 1.81 & $2.78 \mathrm{E}-03$ \\
\hline BPSS0304 & malH & protein of unknown function & 2.60 & $3.60 \mathrm{E}-04$ & 1.93 & $1.38 \mathrm{E}-03$ \\
\hline BPSS0305 & malG & ketol-acid reductoisomerase & 2.51 & $3.20 \mathrm{E}-04$ & 1.95 & $9.39 \mathrm{E}-04$ \\
\hline BPSS0306 & malF & multifunctional polyketide-peptide syntase & 2.67 & $5.32 \mathrm{E}-04$ & 2.14 & $1.38 \mathrm{E}-03$ \\
\hline BPSS0307 & malE & gamma-aminobutyraldehyde dehydrogenase & 2.81 & $1.53 \mathrm{E}-04$ & 2.35 & $2.60 \mathrm{E}-04$ \\
\hline BPSS0308 & malD & protein of unknown function & 2.75 & $1.55 \mathrm{E}-04$ & 2.23 & $3.46 \mathrm{E}-04$ \\
\hline BPSS0309 & malc & peptide synthase regulatory protein & 2.89 & 8.78E-05 & 2.33 & 2.10E-04 \\
\hline BPSS0310 & malB & protein of unknown function & 2.98 & $1.53 \mathrm{E}-04$ & 2.62 & $2.20 \mathrm{E}-04$ \\
\hline BPSS0311 & malA & multifunctional polyketide-peptide syntase & 3.10 & 5.17E-04 & 2.87 & 4.96E-04 \\
\hline BPSS0312 & malR & LuxR family transcriptional regulator & 1.47 & $6.27 \mathrm{E}-04$ & 1.12 & $2.72 \mathrm{E}-03$ \\
\hline BPSS0317 & & monooxygenase & 1.54 & $1.55 \mathrm{E}-03$ & 2.38 & 6.99E-05 \\
\hline BPSS0325 & & putative membrane protein of unknown function & 0.32 & 2.91E-01 & 1.07 & 3.74E-03 \\
\hline BPSS0337 & & protein of unknown function & 1.38 & $1.24 \mathrm{E}-03$ & 1.91 & $1.20 \mathrm{E}-04$ \\
\hline BPSS0623 & & outer membrane efflux protein & 2.09 & 5.17E-04 & 2.27 & 2.10E-04 \\
\hline
\end{tabular}


Table 2 Genes with increased expression in either the bprR and/or bprS single mutants (Continued)

\begin{tabular}{|c|c|c|c|c|c|c|}
\hline BPSS0624 & $\operatorname{macB}$ & macrolide-specific ABC-type efflux carrier & 1.95 & $1.61 \mathrm{E}-03$ & 2.22 & 4.96E-04 \\
\hline BPSS0625 & & drug-efflux protein & 1.97 & 6.27E-04 & 2.15 & 2.33E-04 \\
\hline BPSS0685 & & protein of unknown function & 1.21 & $6.63 \mathrm{E}-04$ & 0.89 & 5.35E-03 \\
\hline BPSS0686 ${ }^{\mathrm{a}}$ & & $\begin{array}{l}\text { Predicted 5,10-methylene tetrahydromethanopterin } \\
\text { reductase }\end{array}$ & 3.39 & $1.14 \mathrm{E}-07$ & 0.35 & $1.71 \mathrm{E}-01$ \\
\hline BPSS0686a & & protein of unknown function & 5.16 & 8.78E-05 & -0.47 & $5.88 \mathrm{E}-01$ \\
\hline BPSS0687 ${ }^{a}$ & & sensor kinase protein & 5.89 & $7.90 \mathrm{E}-09$ & 1.46 & $2.89 \mathrm{E}-04$ \\
\hline BPSS0688 ${ }^{\mathrm{a}}$ & & response regulator protein & 4.56 & 9.34E-09 & 4.70 & 7.98E-09 \\
\hline BPSS0689 & & protein of unknown function & 7.12 & 7.90E-09 & 7.78 & 5.57E-09 \\
\hline BPSS0690 & & protein of unknown function & 6.45 & 1.06E-08 & 6.49 & 9.89E-09 \\
\hline BPSS0692 & & $\begin{array}{l}\text { fumarylacetoacetate (FAA) hydrolase family } \\
\text { protein }\end{array}$ & 2.26 & $1.55 \mathrm{E}-04$ & 2.16 & 2.10E-04 \\
\hline BPSS0693 & & $\begin{array}{l}\text { fumarylacetoacetate (FAA) hydrolase family } \\
\text { protein }\end{array}$ & 2.07 & $1.53 \mathrm{E}-04$ & 1.88 & 2.10E-04 \\
\hline BPSS0694 & hpcC & $\begin{array}{l}\text { 5-carboxymethyl-2-hydroxymuconate } \\
\text { semialdehyde dehydrogenase }\end{array}$ & 2.14 & $2.48 \mathrm{E}-05$ & 2.18 & $1.82 \mathrm{E}-05$ \\
\hline BPSS0695 & $h p c B$ & 3,4-dihydroxyphenylacetate 2,3 -dioxygenase & 1.81 & 8.07E-05 & 1.84 & 4.84E-05 \\
\hline BPSS0696 & $h p c D$ & $\begin{array}{l}\text { 5-carboxymethyl-2-hydroxymuconate delta- } \\
\text { isomerase }\end{array}$ & 2.19 & $1.53 \mathrm{E}-04$ & 1.98 & 2.44E-04 \\
\hline BPSS0697 & hpcG & 2-oxo-hepta-3-ene-1,7-dioic acid hydratase & 1.85 & 2.01E-04 & 1.89 & $1.69 \mathrm{E}-04$ \\
\hline BPSS0698 & hpcH & 2,4-dihydroxyhept-2-ene-1,7-dioic acid aldolase & 2.01 & $1.55 \mathrm{E}-04$ & 1.99 & 1.67E-04 \\
\hline BPSS0724 & & protein of unknown function & 0.83 & 7.33E-03 & 1.09 & $1.38 \mathrm{E}-03$ \\
\hline BPSS0755 & & LysR family regulatory protein & 0.57 & $3.11 \mathrm{E}-02$ & 1.03 & $1.23 \mathrm{E}-03$ \\
\hline BPSS0796A & & H-NS-like protein & 1.71 & $2.38 \mathrm{E}-03$ & 4.39 & $1.27 \mathrm{E}-06$ \\
\hline BPSS0797 & & ICIR family regulatory protein & 1.03 & $6.40 \mathrm{E}-02$ & 3.95 & $1.96 \mathrm{E}-05$ \\
\hline BPSS0798 & & protein of unknown function & 0.68 & $1.60 \mathrm{E}-01$ & 3.35 & $2.11 \mathrm{E}-05$ \\
\hline BPSS0799 & & diguanylate phosphodiesterase & 1.04 & $9.65 \mathrm{E}-03$ & 4.48 & $1.31 \mathrm{E}-07$ \\
\hline BPSS0828 & & protein of unknown function & 0.82 & $3.54 \mathrm{E}-02$ & 1.21 & 5.35E-03 \\
\hline BPSS0852 & & inosine-uridine preferring nucleoside hydrolase & 1.60 & 6.57E-03 & 1.74 & 3.49E-03 \\
\hline BPSS0941 & & protein of unknown function & 1.07 & 8.73E-03 & 1.33 & 2.78E-03 \\
\hline BPSS0946 & penA & beta-lactamase precursor & 1.94 & $2.38 \mathrm{E}-03$ & 2.65 & 2.44E-04 \\
\hline BPSS1038 & & protein of unknown function & 0.04 & 9.47E-01 & 1.66 & 5.01E-03 \\
\hline BPSS1239 & & peptidase & 0.33 & $6.92 \mathrm{E}-01$ & 2.76 & $2.53 \mathrm{E}-03$ \\
\hline BPSS1250 & & acetylpolyamine aminohydrolase & 0.95 & $2.14 \mathrm{E}-02$ & 1.10 & 9.81E-03 \\
\hline BPSS1275 & & RNA polymerase sigma factor & 1.25 & 7.92E-03 & 1.51 & 2.99E-03 \\
\hline BPSS1296 & & O-methyltransferase-like protein & 0.88 & $1.11 \mathrm{E}-02$ & 1.05 & 4.84E-03 \\
\hline BPSS1553 & bprP & Transcriptional regulator & 1.57 & 2.04E-03 & 1.19 & 8.84E-03 \\
\hline BPSS1554 & bprQ & Protein associated with $b p r P$ & 1.43 & $1.28 \mathrm{E}-03$ & 1.31 & 2.27E-03 \\
\hline BPSS1862 & & $A B C$ transport system, ATP-binding protein & 1.70 & 8.43E-03 & 1.71 & 7.39E-03 \\
\hline BPSS1866 & & lipoprotein & 0.21 & $5.80 \mathrm{E}-01$ & 1.44 & 2.10E-03 \\
\hline BPSS1867 & & protein of unknown function & 1.42\# & $1.21 \mathrm{E}-02$ & 2.20 & $9.10 \mathrm{E}-04$ \\
\hline BPSS1980 & & protein of unknown function & 0.66 & $1.61 \mathrm{E}-02$ & 1.31 & 2.44E-04 \\
\hline BPSS1996 & & protein of unknown function & 1.13 & $8.44 \mathrm{E}-02$ & 2.84 & 8.95E-04 \\
\hline
\end{tabular}


Table 2 Genes with increased expression in either the bprR and/or bprS single mutants (Continued)

\begin{tabular}{llllll}
\hline BPSS2162 & protein of unknown function & 0.42 & $5.50 \mathrm{E}-01$ & $\mathbf{2 . 1 3}$ & $\mathbf{6 . 1 4 \mathrm { E } - 0 3}$ \\
BPSS2307 & amidase & 0.61 & $1.05 \mathrm{E}-01$ & $\mathbf{1 . 4 7}$ & $\mathbf{1 . 9 2 \mathrm { E } - 0 3}$ \\
BPSS2308 & protein of unknown function & $\mathbf{1 . 0 1}$ & $\mathbf{1 . 2 6 E}-\mathbf{0 3}$ & $\mathbf{1 . 9 7}$ & $\mathbf{1 . 1 4 E - 0 5}$ \\
\hline
\end{tabular}

Genes were identified as differentially expressed if they showed $>2$-fold expression change $\left(\log _{2}>1.0\right)$ compared to the wild-type strain with a False Discovery Rate (FDR) of $<0.01$. All significant gene expression changes are shown in bold and the locus tag, gene name and description are shown in bold when significant expression changes were observed for both mutants

ancreased RNA expression also observed in the bprRS double mutant (Table 1)

\#Genes showing increased expression of $>2$-fold with a FDR of $>0.01$ and $<0.05$

unknown function), are located on chromosome 2 within a predicted prophage. The remaining two genes differentially expressed in the $b p r R S$ double mutant encoded a predicted ATPase (bpsl0145) and a phage membrane protein (bpsl0146) that were within a large region on chromosome 1 also containing a predicted prophage.

\section{Transcriptomic analyses of the bprS, bprR single gene mutants}

In order to identify gene expression changes that resulted from perturbation of the BprRS system via inactivation of $b p r S$, encoding the SK, or $b p r R$, encoding the $\mathrm{RR}$, we compared the transcriptomes of the bprS and $\operatorname{bprR}$ mutants with the wild-type strain. A total of 170 genes were differentially expressed in one or both of the single mutants and 57 genes showed increased expression and 16 reduced expression ( $\geq 2$-fold change in expression at FDR <0.01) in both the bprS mutant and the bprR mutants (Fig. 3, Tables 2 and 3); thus, these gene lists show a high degree of similarity (Fisher's exact

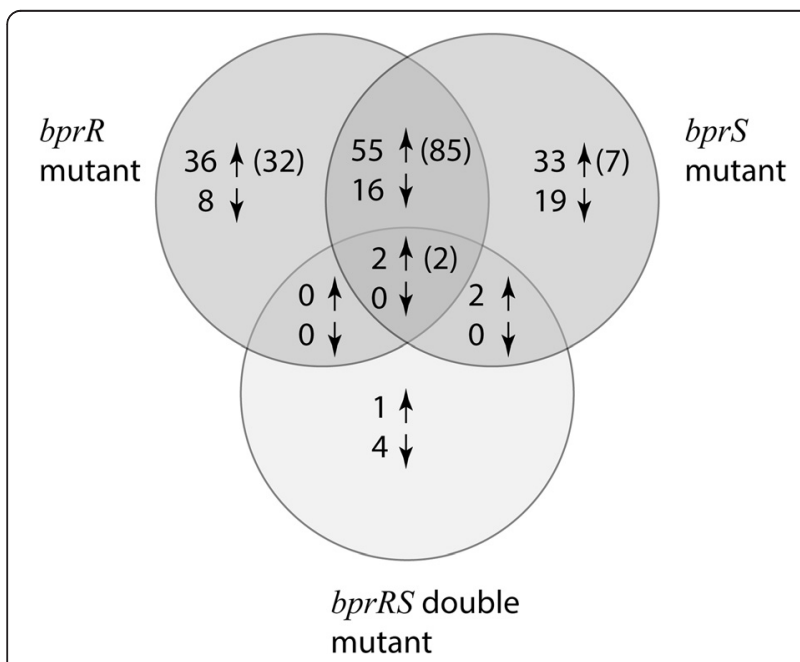

Fig. 3 A Venn diagram showing the number of B. pseudomallei genes with increased expression (up arrow) or with reduced expression (down arrow) in each of the bprR, bprS and bprRS double mutants. Genes were identified as differentially expressed if they showed $>2$-fold expression change $\left(\log _{2}>1.0\right)$ compared to the wild-type strain with a False Discovery Rate (FDR) of $<0.01$. The total number of genes in each mutant showing increased expression ( $>2$-fold) with a more relaxed FDR of $<0.05$ are shown in brackets test; $P<0.001)$. Moreover, when a slightly less stringent FDR of $<0.05$ was applied to the initial gene list generated, 103 of the 171 genes identified were differentially expressed in both the bprS mutant and the bprR mutant (87 increased and 16 decreased) (Fig. 3, Tables 2 and 3). Genes identified with increased expression in the bprS and $\operatorname{bprR}$ single mutants included many involved in the production of secondary metabolites; bpsl3323-3329 and bpss0689-0690 involved in fatty acid biosynthesis, bpss0692-0698 involved in the degradation of aromatic compounds, and all the genes within the malleilactone biosynthesis locus (bpss0298-bpss0312).

Two genes encoding methyl-accepting chemotaxis proteins (MCPs) (bpsl1829 and tar) and at least 19 genes required for flagella biosynthesis (including fliA encoding the flagella biosynthesis sigma factor) showed increased expression in the bprS single mutant; the majority of these also showed increased expression in the $\operatorname{bprR}$ mutant although mostly with FDR values between 0.01 and 0.05 (Tables 2 and 4). Genes involved in antibiotic resistance were also increased in expression and included bpeR (encoding a TetR family regulator), bpe $A$ and $b p e B$ that together encode the resistancenodulation-division (RND) multidrug efflux pump BpeAB-OprA [24]. Other genes involved in antibiotic resistance that were over-expressed included the gene bpsl2708, encoding a putative metallo- $\beta$-lactamase, and pen $A$ that encodes a class A $\beta$-lactamase conferring resistance to ceftazidime $[25,26]$. Three genes (bpss0623, $m a c B$ and bpss0625) encoding an $\mathrm{ABC}$ transporter/type I secretion system predicted to be involved in drug resistance [27] were also over-expressed in the mutants. Genes with decreased expression in both the $\operatorname{bprR}$ and bprS mutant included five genes (bpss0515-bpss0520) located within the type 6 secretion system cluster 2 (T6SS-2). This cluster encodes one of six T6SSs produced by B. pseudomallei (designated T6SS-1through to T6SS-6) but only T6SS-1 has been determined to have a role in virulence [28].

Importantly, a large number of regulatory genes were identified as differentially expressed when the BprRS system was perturbed by single gene inactivation. Regulatory genes with increased expression in both the $b p r S$ and $b p r R$ single mutants included fliA and bpeR (discussed above) and 
Table 3 Genes with decreased expression in the bprR and/or bprS single mutants

\begin{tabular}{|c|c|c|c|c|c|c|}
\hline Locus tag & $\begin{array}{l}\text { Gene } \\
\text { name }\end{array}$ & Gene product/description & $\begin{array}{l}\text { bprS mutant } \\
\text { Expression }\left(\log _{2}\right)\end{array}$ & $\begin{array}{l}\text { bprs mutant } \\
\text { FDR }\end{array}$ & $\begin{array}{l}\text { bprR mutant } \\
\text { Expression }\left(\log _{2}\right)\end{array}$ & $\begin{array}{l}\text { bprR mutant } \\
\text { FDR }\end{array}$ \\
\hline BPSL0153 & & putative phage protein & -1.37 & 8.23E-03 & -0.27 & 4.60E-01 \\
\hline BPSL0154 & & phage baseplate assembly protein & -2.44 & $8.06 \mathrm{E}-03$ & -0.60 & 3.10E-01 \\
\hline BPSL0155 & & phage baseplate assembly protein & -1.65 & $2.96 \mathrm{E}-03$ & -0.87 & 4.55E-02 \\
\hline BPSL0156 & & phage baseplate assembly protein & -1.90 & 6.75E-04 & -0.77 & 4.26E-02 \\
\hline BPSL0157 & & phage-encoded modification methylase & -2.80 & 8.98E-04 & -1.14 & $3.72 \mathrm{E}-02$ \\
\hline BPSL0159 & & phage tail completion protein & -0.90 & $1.70 \mathrm{E}-02$ & -1.72 & $1.33 \mathrm{E}-03$ \\
\hline BPSL0169 & & phage terminase, endonuclease subunit & -2.26 & $1.02 \mathrm{E}-03$ & -0.94 & 4.27E-02 \\
\hline BPSL0170 & & phage major capsid protein precursor & -2.19 & 6.09E-03 & -0.94 & 1.08E-01 \\
\hline BPSL0171 & & putative phage capsid scaffolding protein & -2.48 & $8.20 \mathrm{E}-03$ & -0.93 & $1.59 \mathrm{E}-01$ \\
\hline BPSL0347 & & putative insertion element protein & -2.80 & $5.12 \mathrm{E}-03$ & -3.04 & 5.01E-03 \\
\hline BPSL0585 & & protein of unknown function & -1.69 & $2.38 \mathrm{E}-03$ & -2.18 & $1.04 \mathrm{E}-03$ \\
\hline BPSL0742 & & protein of unknown function & -0.67 & 7.95E-02 & -1.25 & $6.20 \mathrm{E}-03$ \\
\hline BPSL0759 & & protein of unknown function & -1.25 & $9.45 \mathrm{E}-03$ & -0.96 & 2.92E-02 \\
\hline BPSL0761 & & protein of unknown function & -1.19 & $6.70 \mathrm{E}-03$ & -0.85 & $2.91 \mathrm{E}-02$ \\
\hline BPSL1801 & & putative type- 1 fimbrial protein & -1.23 & $4.28 \mathrm{E}-03$ & -1.89 & $2.60 \mathrm{E}-04$ \\
\hline BPSL2112 & & hydroxydechloroatrazine ethylaminohydrolase & -1.47 & 4.03E-02 & -2.16 & $7.22 \mathrm{E}-03$ \\
\hline BPSL2113 & & putative purine catabolism-related protein & -1.41 & 7.63E-03 & -2.33 & 7.13E-04 \\
\hline BPSL2114 & & protein of unknown function & -1.48 & $5.36 \mathrm{E}-03$ & -2.26 & 3.27E-04 \\
\hline BPSL2115 & & ureidoglycolate hydrolase & -1.13 & $1.61 \mathrm{E}-02$ & -1.69 & $2.22 \mathrm{E}-03$ \\
\hline BPSL2116 & & allantoicase & -1.30 & 8.28E-03 & -1.84 & $9.39 \mathrm{E}-04$ \\
\hline BPSL2117 & & putative uricase & -1.04 & 3.97E-02 & -1.73 & $3.81 \mathrm{E}-03$ \\
\hline BPSL2118 & & protein of unknown function & -1.18 & $9.24 \mathrm{E}-03$ & -1.83 & 6.37E-04 \\
\hline BPSL2508 & & protein of unknown function & -1.48 & $6.03 \mathrm{E}-03$ & -1.07 & $2.36 \mathrm{E}-02$ \\
\hline BPSL2708 & & $\begin{array}{l}\text { putative exported metallo-beta-lactamase-family } \\
\text { protein }\end{array}$ & -1.08 & $6.27 E-04$ & -0.59 & $1.62 \mathrm{E}-02$ \\
\hline BPSL2972 & & ICIR family regulatory protein & -1.02 & $2.38 \mathrm{E}-03$ & -0.82 & 8.20E-03 \\
\hline BPSL3171 & & protein of unknown function & -1.25 & 6.57E-03 & -0.92 & $2.71 \mathrm{E}-02$ \\
\hline BPSS0063 & $d c t D$ & $\begin{array}{l}\text { C4-dicarboxylate transport transcriptional } \\
\text { response regulator }\end{array}$ & -1.21 & $3.44 \mathrm{E}-03$ & -0.95 & $1.32 \mathrm{E}-02$ \\
\hline BPSS0070 & & IS30 transposase & -0.66 & $4.42 \mathrm{E}-02$ & -1.06 & $6.19 \mathrm{E}-03$ \\
\hline BPSS0169 & & protein of unknown function & -1.72 & 7.67E-03 & -1.44 & $1.90 \mathrm{E}-02$ \\
\hline BPSS0515 & & $\begin{array}{l}\text { type VI secretion-associated protein, ImpA } \\
\text { family }\end{array}$ & -1.86 & 2.63E-03 & -1.75 & $5.74 \mathrm{E}-03$ \\
\hline BPSS0516 & & type VI secretion protein & -1.79 & $8.28 \mathrm{E}-03$ & -1.98 & $9.46 \mathrm{E}-03$ \\
\hline BPSS0517 & EvpB & protein of unknown function & -2.03 & $1.85 \mathrm{E}-04$ & -1.76 & $5.84 \mathrm{E}-04$ \\
\hline BPSS0518 & & type VI secretion protein & -1.98 & 5.17E-04 & -1.74 & $1.41 \mathrm{E}-03$ \\
\hline BPSS0520 & & type VI secretion protein & -1.36 & $9.44 \mathrm{E}-04$ & -1.27 & 2.01E-03 \\
\hline BPSS1034 & & protein of unknown function & -1.12 & $7.89 \mathrm{E}-03$ & -1.69 & 8.11E-04 \\
\hline BPSS1035 & & protein of unknown function & -1.74 & $5.66 \mathrm{E}-03$ & -2.24 & $2.78 \mathrm{E}-03$ \\
\hline BPSS1080 & & bacteriophage baseplate assembly protein J & -1.47 & $8.24 \mathrm{E}-03$ & -0.54 & 1.90E-01 \\
\hline BPSS1085 & & bacteriophage major tail tube protein & -1.47 & $7.30 \mathrm{E}-03$ & -0.75 & 8.02E-02 \\
\hline BPSS1588 & & protein of unknown function & -1.57 & $3.16 \mathrm{E}-02$ & -2.21 & 5.01E-03 \\
\hline
\end{tabular}


Table 3 Genes with decreased expression in the bprR and/or bprS single mutants (Continued)

\begin{tabular}{|c|c|c|c|c|c|c|}
\hline BPSS1740 & $\operatorname{lip} B$ & lipase chaperone & -0.83 & 3.87E-02 & -1.41 & 5.01E-03 \\
\hline BPSS2136 & & Family S43 non-peptidase protein & -1.24 & $2.38 \mathrm{E}-03$ & -1.16 & 3.97E-03 \\
\hline BPSS2138 & oppD & $\begin{array}{l}\text { oligopeptide transport ATP-binding ABC } \\
\text { transport protein }\end{array}$ & -1.11 & 9.63E-03 & -1.20 & 9.13E-03 \\
\hline BPSS2296 & & transport protein & -2.21 & $3.62 \mathrm{E}-03$ & -1.87 & 1.14E-02 \\
\hline
\end{tabular}

Genes were identified as differentially expressed if they showed $>2$-fold expression change $\left(\log _{2}<-1.0\right)$ compared to the wild-type strain with a False Discovery Rate (FDR) of $<0.01$. All significant gene expression changes are shown in bold and the locus tag, gene name and description are shown in bold when significant expression changes were observed for both mutants

malR (bpss0312), encoding a regulator that shares identity (97\%) with MalR in Burkholderia thailandensis, an orphan LuxR homolog that activates the malleilactone biosynthesis genes independently of acyl-homoserine lactone and quorum sensing systems $[29,30]$. The genes $\operatorname{bpr} P$ (bpss1553), encoding a transmembrane regulator, and the adjacent gene $\operatorname{bpr} Q$, encoding a transmembrane protein, involved in the control of the $\mathrm{BsaN}$ virulence regulon were also over-expressed. Importantly, the BsaN virulence regulon includes genes encoding the type III secretion system locus 3 (TTSS3) [31, 32]. The expression of bpss0799 in both the bprR and bprS single mutants was also increased (Table 4); the encoded protein contains an EAL domain and shares significant identity with cyclic diguanylate phosphodiesterases, which are known to control motility and biofilm formation in a number of bacteria [33]. Other regulatory genes with increased expression but in only the $b p r R$ mutant were bpss0797 encoding an IclR family protein, bpss0755 encoding a LysR family protein, and bpsl1564 that encodes a putative transcriptional regulatory protein (Table 4). Only one regulatory gene (bpss00070, encoding an IS30 transposase) had decreased expression in the bprR mutant. Regulatory genes that were reduced in expression but only in the bprS single mutant included bpsl2972, encoding an

Table 4 Regulatory genes differentially expressed in the bprR and/or bprS single mutants

\begin{tabular}{|c|c|c|c|c|c|}
\hline Locus tag/gene & Description/predicted function & $\begin{array}{l}\text { Expression in } \\
\text { bprS mutant }\end{array}$ & $\begin{array}{l}\text { Expression in } \\
\text { bprR mutant }\end{array}$ & & \\
\hline \multicolumn{4}{|c|}{ Two component signal transduction systems } & \multicolumn{2}{|l|}{ Class/Function } \\
\hline BPSL1829 & $\begin{array}{l}\text { methyl-accepting chemotaxis } \\
\text { protein }\end{array}$ & Increased & Increased\# & \multicolumn{2}{|l|}{ MCP/Chemotaxis } \\
\hline BPSS0063 dctD & C4-dicarboxylate transport protein & Decreased & NS & \multicolumn{2}{|l|}{ RR/Receiver } \\
\hline BPSS0215 tar & $\begin{array}{l}\text { methyl-accepting } \\
\text { chemotaxis protein }\end{array}$ & Increased & Increased\# & \multicolumn{2}{|l|}{ MCP/Chemotaxis } \\
\hline BPSS0687 bprs & sensor kinase protein & Increased & Increased & \multicolumn{2}{|l|}{ HKTransmitter } \\
\hline BPSS0688 bprR & response regulator protein & Increased & Increased & \multicolumn{2}{|l|}{ RR/Receiver } \\
\hline \multicolumn{4}{|c|}{ One component regulators } & Domain-input & Domain-output \\
\hline BPSL0812 bpeR & TetR family regulatory protein & Increased & Increased & Not known & TetR_N-DNA binding \\
\hline BPSL1564 & transcriptional regulatory protein & NS & Increased & Not known & HTH_26-DNA binding \\
\hline BPSL2972 & ICIR family regulatory protein & Decreased & NS & Ic|R/Small-molecule binding & HTH_ICIR-DNA binding \\
\hline BPSL3291 fliA & flagellar biosynthesis sigma factor & Increased & Increased & Not known & Sigma70 -DNA binding \\
\hline BPSS0070 & IS30 transposase & NS & Decreased & Not known & HTH_38-DNA binding \\
\hline BPSS0312 malR & LuxR transcriptional regulator & Increased & Increased & $\begin{array}{l}\text { Autoind_bind-Small-molecule } \\
\text { binding }\end{array}$ & GerE-DNA binding \\
\hline BPSS0755 & LysR family regulatory protein & NS & Increased & $\begin{array}{l}\text { LysR_substrate- Small-molecule } \\
\text { binding }\end{array}$ & HTH_1-DNA binding \\
\hline BPSS0797 & ICIR family regulatory protein & NS & Increased & Ic|R/Small-molecule binding & HTH_ICIR-DNA binding \\
\hline BPSS0799 & Diguanylate phosphodiesterase & Increased & Increased & & EAL/Di-guanylate cyclase \\
\hline BPSS1553 bprP & Transcriptional regulator & Increased & Increased & & Trans_reg_C/DNA-binding \\
\hline
\end{tabular}

Genes were identified as differentially expressed if they showed $>2$-fold expression change $\left(\log _{2}<-1.0\right)$ compared to the wild-type strain with a False Discovery Rate (FDR) of $<0.01$

\#Genes showing increased expression of $>2$-fold with a FDR of $>0.01$ and $<0.05$ 
IclR family protein, and $\operatorname{dct} D$, encoding a C4dicarboxylate transport transcriptional response regulator (Table 4).

\section{Perturbation of the BprRS TCSTS affects B. pseudomallei motility}

In the mutants with a single inactivation in either $b p r S$ or $b p r R, 21$ genes involved in flagella biosynthesis were increased in expression, located in four different locations on chromosome 1 (Table 2). In addition, two genes encoding methyl-accepting chemotaxis proteins (bpsl1829 and tar) showed increased expression, and there was decreased expression of the type- 1 fimbrial gene, bpsl1801 (Table 3) predicted to be involved in attachment to surfaces. Accordingly, we analysed the $b p r S$ mutants (bprS::Tn5 and the bprS directed mutant), the bprR directed mutant, the parent strain K96243, as well as the bprRS double mutant, for their ability to migrate or swarm in a coordinated manner on solid medium. The parent strain K96243 and the bprRS double mutant both demonstrated a capacity for rapid swarming, with the leading edge of the swarming population migrating to the edge of the agar plate (diameter $80 \mathrm{~mm}$ ) after $18 \mathrm{~h}$ at $37{ }^{\circ} \mathrm{C}$ (Fig. 4). However, all strains with either bprS or bprR inactivated demonstrated a significantly reduced ability to swarm in a coordinated manner (Fig. 4). To confirm that the reduced swarming motility was due to perturbation of the BprRS system, we complemented the bprS directed mutant with the complete bprRS operon in trans. Interestingly, we were unable to clone either $\operatorname{bprS}$ or $\operatorname{bprR}$ into the multicopy plasmid pBHR1 alone. Swarming motility was fully restored in the bprS(bprRS) complemented strain, whereas the bprS mutant harbouring empty vector (pBHR1) alone retained the reduced motility phenotype (Fig. 4). These data show that inactivation of a single component in the BprRS TCSTS can reduce the swarming ability of B. pseudomallei.

\section{Discussion}

We have identified a putative TCSTS in B. pseudomallei strain K96243 that is encoded by bprS (bpss0687) encoding the SK, and bprR (bpss0688) encoding the RR. Inactivation of the entire BprRS system did not result in changes to virulence or motility, and RNA expression analysis of the bprRS double mutant identified very few genes that were differentially expressed compared to the expression in the parent strain K96243. Genes identified as differentially expressed in the bprRS double mutant included one (bpss0686) adjacent to the bprS gene, encoding a predicted 5, 10-methylene tetrahydromethanopterin reductase that is required for one carbon metabolism [23]. Five genes that encoded phage-related proteins were also identified. Thus, our analysis suggests that the BprRS TCSTS regulon is small but it is possible

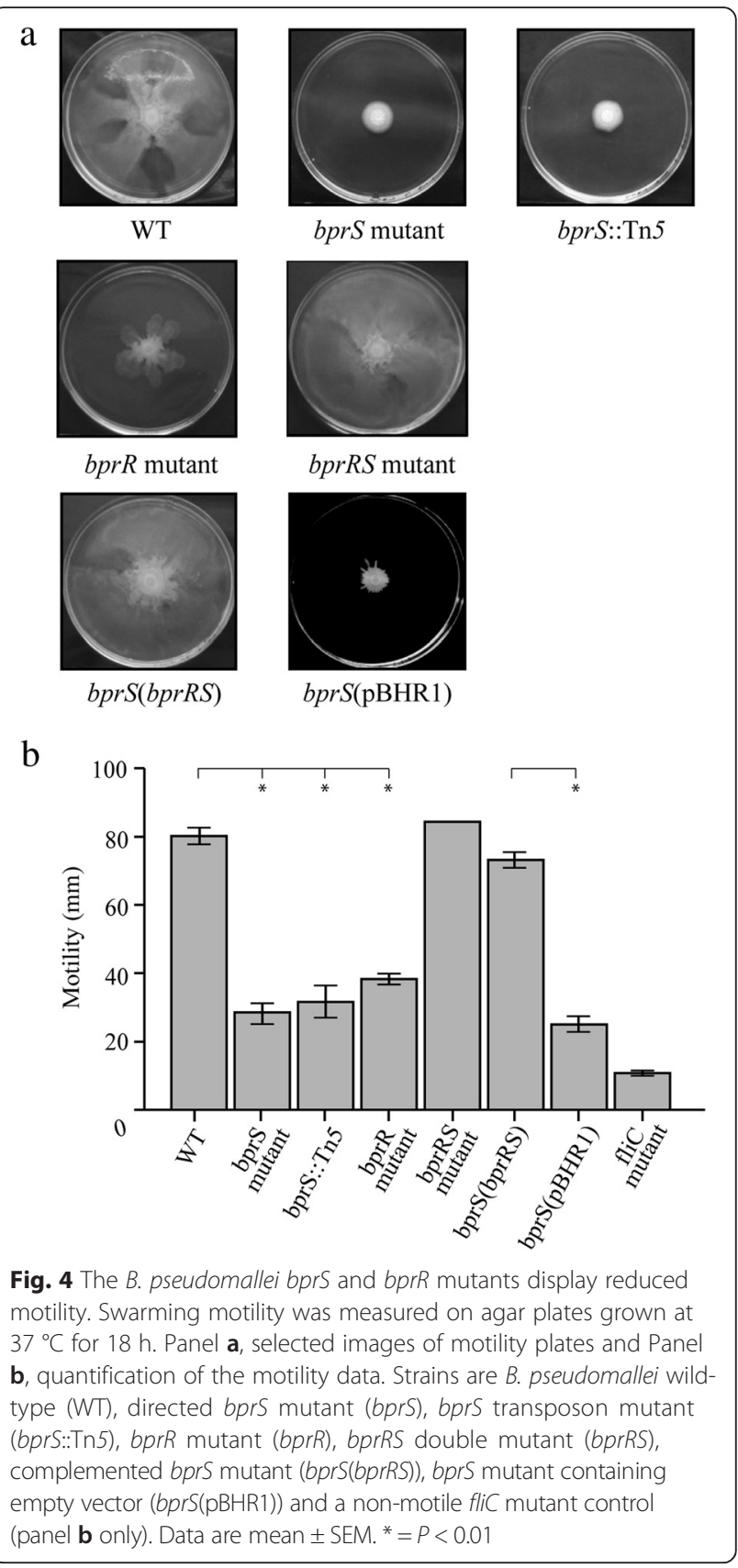

that under different growth conditions, such as during growth in a host or the environment, other genes may be identified that belong to the BprRS regulon.

In contrast, inactivation of a single component (bprS or $b p r R$ ) of the BprRS TCSTS resulted in the differential expression of a large number of genes. More than 70 genes were differentially expressed in both the bprS and bprR mutant and included those involved in flagella biosynthesis, malleilactone biosynthesis, antibiotic resistance, chemotaxis and regulation. In addition, phenotypic assays showed that the $b p r S$ and $b p r R$ mutants displayed reduced growth in mice and reduced swarming motility. 
Together, these results clearly demonstrate that perturbation of the BprRS system, but not inactivation of the whole system, attenuates $B$. pseudomallei. We hypothesize that the changes observed as a result of perturbation of the BprRS TCSTS arise through cross-regulation with one or more of the 60 TCSTS encoded on the B. pseudomallei genome [15]. A number of interactions between TCSTS have been identified in Escherichia coli; in vitro phosphorylation assays showed that phosphorylation of RRs by non-cognate SKs was observed for at least 21 pairs [34]. While most E. coli cross-talk interactions are weak [34], strong cross-talk has been observed between a number of systems, including $\mathrm{CreC}$ and $\mathrm{PhoB}$ and the $\mathrm{PmrA} / \mathrm{B}$ and QseB/C systems of $E$. coli $[35,36]$ Interactions between PhoB, PmrA/B and QseB/C happen at multiple levels including phosphorylation, dephosphorylation and DNA binding. The E. coli QseC SK normally acts to dephosphorylate (and deactivate) its cognate RR QseB, but QseB can be phosphorylated by $\mathrm{PmrB}$ at relatively high levels [36] and the binding of both RRs at the qseBC promoter is likely to be required for normal gene expression. In the absence of QseC the phosphorylating activity of PmrB on QseB is uncontrolled, leading to increased expression of the QseBC TCSTS and decreased expression of a range of virulence genes including those involved in pilin and flagellin synthesis. Importantly, while an $E$. coli qseC mutant was non-motile and attenuated for virulence, the single $q s e B$ and the double qseBC mutants showed wild-type virulence and motility [37]. Cross-regulation has been implicated in at least three $E$. coli TCSTS that affect flagella synthesis and motility, including predicted interactions between ArcAB and another unidentified TCSTS [38]. Therefore, we propose that in the absence of both BprR and BprS (i.e. the bprRS double mutant) only the expression of genes within the BprRS regulon is affected. However, in the absence of BprS, BprR is phosphorylated by one or more, non-cognate sensor kinases and interacts with genes outside the BprRS regulon. Conversely, we predict that in the absence of BprR, BprS phosphorylates one or more, non-cognate response regulators. Moreover, given that a large subset of genes was differentially expressed in both the bprR and bprS mutants, we propose that the majority of cross-talk occurs largely with a single, as yet unidentified, TCSTS cognate pair. This cross-talk then leads to a cascade of dysregulation, including altered expression of genes encoding other regulators.

Phenotypic analysis of the mutants revealed that the bprS and bprR mutants were attenuated for swarming motility. In both mutants many flagella biosynthesis genes showed increased expression compared to the wild-type strain; suggesting that altered motility resulted from incorrect levels of flagella proteins or dysregulated timing of expression. Furthermore, genes within the flagella-associated locus, including fliC encoding the flagella subunit, were not changed in expression compared to that in the parent strain K96243 supporting the proposition that the altered motility of the BprS and $B p r R$ mutants may have been affected by an imbalance in the expression of the flagella biosynthesis and structural components. In E. coli and other bacteria, flagella synthesis involves the action of numerous and complex TCSTS interactions, and we predict similar interactions between regulatory factors is also likely to be essential for the co-ordinated movement of B. pseudomallei. The gene bpsS0799, encoding a protein with an EAL domain characteristic of cyclic diguanylate phosphodiesterases, was increased in expression in both the bprS and $b p r R$ mutants. Cyclic diguanylate phosphodiesterases negatively control levels of bis- $\left(3^{\prime}-5^{\prime}\right)$-cyclic dimeric guanosine monophosphate (c-di-GMP) and, together with the positive regulator diguanylate cyclase, initiate the c-diGMP signalling system in bacteria. The global second messenger c-di-GMP then binds to specific effector molecules that target, and subsequently affect the expression of a wide range of genes involved in cellular functions including motility, biofilm formation and the production of fimbriae [33]. A previous study identified another $B$. pseudomallei gene (cdpA or bpsl1263) as encoding the cyclic diguanylate phosphodiesterase involved in flagella function and motility [39]. However, our own bioinformatic analysis (data not shown) indicates that bpsl1263 encodes a protein with both an EAL and a GGDEF domain, the latter domain being characteristic of diguanylate cyclases. Other regulatory genes with increased expression in the $b p r S$ and $b p r R$ mutants included two genes encoding predicted MCPs, bpsl1829 and tar. MCPs are the trans-membrane sensor proteins of the chemotaxis pathway that controls bacterial movement in response to available nutrients or other environmental stimuli [40]. In E. coli, MCPs directly transfer phosphate to the TCSTS SK CheA that then transfers the phosphate to one of two RRs, CheY or CheB. Phosphorylated CheY interacts directly with the flagella motor and causes a directional change, whereas phosphorylated CheB acts a methylesterase on the signalling MCP and modulates the amount of signal [41]. The MCP Tar sensors induce bacterial cells to move towards aspartate/ maltose and away from nickel/cobalt [42]. Bioinformatic analysis did not provide any information on the type of sensor the bpsl1829 gene encodes, but we predict that dysregulation of the expression of either MCP is likely to have an effect on motility. Although no studies have been conducted on chemotaxis mutants in any Burkholderia species, a study in a close relative, Ralstonia solanacearum, showed that a cheA mutant displayed significantly reduced virulence [43].

The genes $\operatorname{bprP}$ and $\operatorname{bprQ}$, involved in the BsaN virulence regulon, both displayed increased expression when 
the BprRS TCSTS was perturbed. A recent transcriptomic study of a $B$. pseudomallei bsaN deletion mutant elucidated components of the BsaN virulence-associated regulatory system [32]. It is proposed that BprP directly activates the Ara-C like regulatory protein $\mathrm{BsaN}$ that, together with the T3SS3 chaperone BicA, act as a dualfunction regulatory complex that controls the expression of the T6SS-1 (via activation of the VirAG TCSTS) and the T3SS3 effectors (bopA, bopC and bopE). In addition, in the $b s a N$ mutant the TTSS3 genes showed increased expression, while the genes involved in malleilactone (bpss0303-0311) and flagella biosynthesis (bpsl0281, bpsl3319, bpsl3320, bpsl3321) showed decreased expression [32]. In our study, we observed an increase in expression of $\operatorname{bpr} P$ and $\operatorname{bpr} Q$, but not the gene encoding the chaperone BicA. We also observed an increase in expression of malleilactone-associated and flagellaassociated genes, but no significant change in expression of genes associated with the T3SS3 and T6SS-1. Nevertheless, it is possible that an imbalance in the expression of the proteins that initiate the transcription of bsaN (BprP/BicA) may have an effect on the expression of some genes within the BsaN regulon.

Perturbation of the BprRS TCSTS reduced the in vivo fitness of B. pseudomallei and this may, or may not have been directly associated with the loss of motility. An initial report demonstrated that a non-flagellated $f l i C \mathrm{mu}-$ tant constructed in B. pseudomallei strain 1026b was not attenuated for virulence in BALB/c mice, diabetic rats or Syrian hamsters $[44,45]$. In contrast, a $f l i C \mathrm{mu}-$ tant of a more virulent strain of B. pseudomallei (KHW) was attenuated for virulence in BALB/c mice [46].

\section{Conclusions}

Phenotypic and transcriptomic analyses of a newly identified TCSTS BprRS, revealed that perturbation of the system via inactivation of the SK BprS or the RR BprR led to a reduction in virulence and reduced motility, as well as a wide range of gene expression changes. Our results support the concept that B. pseudomallei TCSTS regulatory networks can interact and show that selective perturbation of these systems can lead to attenuation of B. pseudomallei. Together our results highlight the need for further systematic studies of B. pseudomallei TCSTS regulation and show that targeting a single TCSTS component can attenuate virulence.

\section{Methods}

\section{Bacterial strains, plasmids and culture conditions}

The B. pseudomallei strain K96243 is a human clinical isolate obtained from Thailand [15]. B. pseudomallei directed mutants were generated by double cross-over insertional mutagenesis using recombinant derivatives of the $\lambda$ pir-dependent plasmid pDM4 [47]. All pDM4 derivatives were maintained in E. coli SM10 $\lambda$ pir (thi thr leu tonA lacY supE recA RP4-2-Tc::Mu::Km pir), or E. coli S17-1 $\lambda$ pir (thi pro hsdR hsdM1 recA RP4-2Tc::Mu-Km::Tn7 pir). For some clonings, pBlueScriptSK(Stratagene) was used as an intermediate vector prior to transfer of the insert into pDM4. The pBlueScript derivatives were grown in $E$. coli $\mathrm{DH} 5 \alpha$ cells $\left(\mathrm{F}^{-}\right.$endA1 hsdR17 $\left(\mathrm{r}_{\mathrm{k}}^{-} \mathrm{m}_{\mathrm{k}}^{-}\right)$glnV44 thi-1 $\lambda^{-}$recA1 gyrA96 relA1 $\Delta(\operatorname{argF}-$ lacZYA)U196 $\phi 80 \mathrm{~d} l a c Z \Delta \mathrm{M} 15)$. The tetracycline resistance gene $\operatorname{tet} A(C)$ was used for selection of $B$. pseudomallei mutants and was isolated from either pUTminiTn5Tc (Biomedal S. L., Spain) or pWH1266 [48]. For complementation, the BprRS operon was cloned into the plasmid pBHR1, a derivative of the mobilizable broad-host-range plasmid pBBR1 [49]. All $E$. coli strains were routinely grown on lysogeny broth (LB) medium with or without selection. B. pseudomallei K96243 and derivatives were grown using either LB, yeast-tryptone medium (2YT), minimal medium (M9), or Ashdown's medium (containing $64 \mu \mathrm{g} / \mathrm{ml}$ gentamicin). All strains were grown at $37{ }^{\circ} \mathrm{C}$ (liquid cultures with $200 \mathrm{rpm}$ agitation).

\section{Construction and screening of $B$. pseudomallei signature- tagged mutagenesis library}

A B. pseudomallei signature-tagged mutagenesis library was constructed using a modified miniTn 5 transposon (Biomedal S.L., Spain). Briefly, 42 unique DNA-tags were amplified from the STM-adapted Tn916 transposons generated by Harper et al. [50] and cloned into the unique NotI site of pUTminiTn5Tc. The 42 uniquelytagged transposons were then separately introduced into B. pseudomallei by conjugation and pools of 42 mutants collected. Each STM pool was then screened for reduced in vivo growth in BALB/c mice [51]. An input pool inoculum of approximately $2 \times 10^{8} \mathrm{CFU}$ was used to inoculate two $8-10$ week old, female BALB/c mice by the i.n. route. DNA recovered from pooled input colonies and pooled output colonies (harvested from spleen), was used to generate digoxygenin-labelled (Roche) DNA probes representing tags present in each sample. Labelled probes were then used in dot blot hybridizations to determine the presence/absence of each mutant in input and output pools as described previously [50].

\section{Generation of bprS, bprR and bprRS double cross-over mutants}

The bprS, bprR and bprRS mutants were constructed by double cross-over insertional mutagenesis using the $\lambda$ pir-dependent vector pDM4 [47] which carries a chloramphenicol resistance gene for selection and the counter-selectable $s a c B$ gene. To generate the $b p r S$ mutagenesis construct, an internal fragment of bprS was disrupted by cloning of the miniTn $5 \operatorname{tet} A(C)$ gene into 
the bprS BglII site. Insertion of the $\operatorname{tet} A(C)$ gene at this $B g l$ III site results in the termination of BprS translation at the second transmembrane region (Fig. 1). Briefly, the primers BAP4787 (5' TTCGTGCTGCAGGATTATC TCGAACGCCATCC 3') containing a PstI site, and BAP4788 (5' CGAATCTCTAGAGTGGAACGGCTCG AACAC 3') containing an $\mathrm{XbaI}$ site, were used to amplify a $981 \mathrm{bp}$ PCR product from within the B. pseudomallei K96243 bprS gene. This PCR fragment, containing an internal BglII site, was digested with PstI and $X b a \mathrm{I}$ and ligated into similarly digested pDM4. Primers BAP3325 (5' CGGCTTAGATCTAGGTCGA GGTGGCC $3^{\prime}$ ) and BAP4629 (5' TCCACCAGATCTATTTGCCGACTACCTTGGTG 3 '), both containing a $B g l I I$ site, were used to amplify the miniTn5 $\operatorname{tet} A(C)$ gene. This PCR product and pDM4 containing the bprS internal fragment were digested with $B g l \mathrm{II}$ and ligated to generate the plasmid pAL603 which was then introduced by transformation into $E$. coli SM10 $\lambda$ pir.

For generation of the bprR mutagenesis construct, pBluescriptSK- was used as an intermediate plasmid prior to cloning into pDM4. Primers BAP6698 (5' GA ACACCCCGGGCGCGAGATCGACATGCCCGGACAC GCC 3') containing an XmaI site, and BAP6699 (5' CGTCGTACTAGTACATGAAGCCGAAGCCCTCGTT GCCG 3') containing an SpeI site, were used to amplify a 1648 bp PCR product from B. pseudomallei K96243 encompassing the entire $b p r R$ gene, 687 bp of upstream and $241 \mathrm{bp}$ of downstream DNA. This PCR product, containing an internal AatII site within $b p r R$ (Fig. 1a) was digested with $X m a \mathrm{I}$ and SpeI and ligated into similarly digested pBluescriptSK-. Primers BAP6700 (5' AAAACAGACGTCTTGCTAACGCAGT 3') and BAP6701 (5' AAAAATGACGTCAGTGGTGAATCC 3'), both containing an AatII site, were used to amplify the $\operatorname{tet} A(C)$ gene from $\mathrm{pWH} 1266$. This product and the pBluescriptSK- derivative containing the $b p r R$ fragment were digested with AatII and ligated to generate the plasmid pBluescriptSK::bprR-tet which was then introduced into $E$. coli $\mathrm{DH} 5 \alpha$ by transformation. This insertion of the tetracycline resistance gene at the internal AatII site causes a truncation of bprR within the initial receiver domain (Fig. 1a). The fragment containing the disrupted $b p r R$ was released from pBluescriptSK::bprR-tet by digestion with XmaI and SpeI and ligated into pDM4, generating the plasmid pAL1067 which was then introduced into $E$. coli SM10 $\lambda$ pir cells.

To generate the bprRS double mutant, up- and downstream regions encompassing the $5^{\prime}$ and $3^{\prime}$ ends of $b p r R$ and $b p r S$ respectively were cloned into pBluescriptSK-, with the $\operatorname{tet} A(C)$ gene from miniTn5 gene inserted between the two fragments. Insertion of this construct into the genome leads to deletion of a 3' segment of bprR (encoding part of the receiver domain and all of the effector domain) as well as deletion of a $5^{\prime}$ segment of bprS (encoding both transmembrane regions and the HAMP and HisKA domains) (Fig. 1b). Briefly, primers BAP6704 (5' TCGACGCCCGGGTCACCGAGCTGCTGACGATCGGC $3^{\prime}$ ) containing an XmaI site, and BAP6705 (5' CGGCGCACTAGTTATCAGACCGACTACGCGCC 3'), containing a SpeI site, were used to amplify a 973 bp PCR fragment including the 3' end of bprS and down-stream flanking DNA. This product was digested with appropriate enzymes and ligated into pBluescriptSK- digested with $\mathrm{XmaI}$ and SpeI and introduced into DH5 $\alpha$ cells. Primers BAP6685 (5' AAAACAGAATTCTTGCTAACGCAGT 3') and BAP6686 (5' AAAAATGAATTCAGTGGTGAATCC $3^{\prime}$ ), both containing an EcoRI site, were used to amplify the $\operatorname{tet} A(C)$ gene from $\mathrm{pWH} 1266$. This product and pBluescriptSKcontaining the DNA fragment containing bprS and flanking region were digested with EcoRI, ligated and introduced into E. coli DH5 $\alpha$. Primers BAP6702 (5' AGCGGCGGGCCCCCGCATGCACCGAGCCC 3') containing an ApaI site, and BAP6703 (5' GAGGCCATCGATTTGATCGTAGACGTCCG 3') containing a ClaI site, were used to amplify a $1021 \mathrm{bp}$ PCR product encompassing the $5^{\prime}$ end of $b p r R$ and up-stream flanking DNA. This product was digested with ApaI and $\mathrm{Cla} \mathrm{I}$ and ligated into the similarly digested pBluescriptSK- containing bprS plus flanking region and the $\operatorname{tet} A(C)$ gene, and then introduced into $E$. coli DH5a cells, generating the plasmid pAL1062. This plasmid was digested with ApaI and SpeI and the fragment containing bprR-tet-bprS was ligated into pDM4. The resulting plasmid, designated pAL1066, was then introduced into E. coli SM10 $\lambda$ pir cells.

Each of the recombinant plasmids pAL603, pAL1067 and pAL1066 was mobilised from E. coli SM10 $\lambda$ pir into B. pseudomallei K96243 by conjugation and putative double cross-over mutants were selected on LB agar containing gentamicin $(8 \mu \mathrm{g} / \mathrm{mL})$ and tetracycline $(25 \mu \mathrm{g} / \mathrm{mL})$. All mutations were confirmed by PCR and sequence analysis (data not shown).

\section{Complementation of the bprS mutant}

The bprS mutant was complemented by cloning an intact copy of the bprRS operon into the multicopy plasmid pBHR1. Primers BAP7136 (5' CGGCGCTTTAA AGGCTCGATACTGACTGCTGCCGGC 3') containing a DraI site, and BAP7137 (5' CGCGCGCCATGGAT CGTCTGACGGCCGAAACC $3^{\prime}$ ) containing an NcoI site, were used to amplify a $2483 \mathrm{bp}$ PCR product from B. pseudomallei K96243. This fragment encoded bprS and $b p r R$ as well as $353 \mathrm{bp}$ of the upstream region predicted to contain the bprRS promoter. The PCR 
product was digested with $\mathrm{DraI}$ and $\mathrm{NcoI}$ and ligated into similarly digested pBHR1, disrupting the cat gene and generating the plasmid pBHR1::bprRS. This plasmid was then introduced into E. coli S-17 $\lambda$ pir and kanamycin resistant, chloramphenicol sensitive clones selected. The pBHR1::bprRS plasmid and empty pBHR1 (negative control) were separately mobilised from $E$. coli S-17 into the bprS mutant by conjugation. Recombinants containing the pBHR1::bprRS plasmid were selected on LB agar containing kanamycin $(1000 \mu \mathrm{g} / \mathrm{mL})$ and tetracycline $(25 \mu \mathrm{g} / \mathrm{mL})$ while those containing the empty pBHR1 plasmid were selected on LB agar containing kanamycin $(1000 \mu \mathrm{g} / \mathrm{mL})$, tetracycline $(25 \mu \mathrm{g} / \mathrm{mL})$ and chloramphenicol $(40 \mu \mathrm{g} / \mathrm{mL})$. Strains containing the correct plasmids were identified by PCR and nucleotide sequence analysis (data not shown). Neither bprR nor bprS alone could be cloned into the pBHR1 plasmid despite numerous attempts.

\section{Competitive in vivo growth assays}

Overnight cultures of $B$. pseudomallei wild-type parent strain K96243 and the bprS mutant were grown in LB to an optical density at $600 \mathrm{~nm}\left(\mathrm{OD}_{600}\right)$ of 0.2 . Equal volumes of K96243 and bprS mutant culture were combined and $20 \mu \mathrm{l}$ (containing approximately $4 \times 10^{5} \mathrm{CFU}$ ) of an appropriate dilution was used to infect three 6-8 weekold female BALB/c mice by the i.n. route. After $24 \mathrm{~h}$, mice were euthanized in accordance with animal ethics requirements. Spleens were harvested, homogenised in phosphatebuffered saline $\mathrm{pH}=7.2$ (PBS) and plated onto $\mathrm{LB}$ agar. After growth at $37^{\circ} \mathrm{C}$ for $24 \mathrm{~h}, 100$ colonies from these in vivo growth plates and 100 colonies representing the input culture were patched onto LB agar with or without tetracycline $(25 \mu \mathrm{g} / \mathrm{ml})$ to determine the proportion of bprS mutant to K96243 wild-type bacteria. The competitive index was calculated as the proportion of mutant to wild-type bacteria recovered from the mouse spleens divided by the proportion of mutant to wild-type bacteria present in the input inoculum.

\section{Virulence assays}

Overnight cultures of the parent strain K96243 and the bprS, bprR and bprRS mutants were subcultured in fresh medium with appropriate antibiotics and grown to mid$\log$ phase to an $\mathrm{OD}_{600}$ of 0.8 (equivalent to $\sim 5.0 \times$ $\left.10^{8} \mathrm{CFU} / \mathrm{ml}\right)$. For the $\mathrm{ID}_{50}$ assays, groups of five $8-10$ week-old BALB/c mice were either inoculated i.n $(1.0 \times$ $10^{6} \mathrm{CFU}$ in $20 \mu \mathrm{l}$ volume $)$ or injected i.p $\left(1.0 \times 10^{3} \mathrm{CFU}\right.$ in $200 \mu$ l volume) with LB containing mid-exponential phase bacteria. For the direct virulence assays, groups of nine 6-8 week-old, female BALB/c mice were infected i.n. with $20 \mu \mathrm{l}$ doses containing approximately $5.0 \times$ $10^{4} \mathrm{CFU}$. Mice were monitored for 10 days for signs of disease and euthanized at the end of the experiment or when moribund, in accordance with animal ethics requirements. The $\mathrm{ID}_{50}$ for the parent strain K96243 and mutant strain was determined using the calculation described by Reed and Muench [52] based on cumulative moribund infections. For direct virulence assays, differences in survival were calculated using Fisher's exact test and differences in time to death determined using the log-rank Mantel-Cox test. Spleens from three mice in each group were harvested, homogenised in PBS and plated onto LB agar. The stability of the mutants was assessed by patching the recovered colonies onto agar plates with or without tetracycline $(25 \mu \mathrm{g} / \mathrm{ml})$. All of the mutations were stable over the time course of the experiment. The virulence of the complementation strain $\operatorname{bprS}(\operatorname{bprRS})$ could not be assessed as the complementation plasmid was highly unstable in the absence of antibiotic selection ( $>90 \%$ plasmid loss over $16 \mathrm{~h}$ ).

\section{RNA purification}

B. pseudomallei parent strain K96243 and the directed bprS, bprR and bprRS mutants were grown overnight at $37^{\circ} \mathrm{C}$ in LB with appropriate antibiotics (K96243 in gentamicin $64 \mu \mathrm{g} / \mathrm{ml}$; mutants in gentamicin $64 \mu \mathrm{g} / \mathrm{ml}$ and tetracycline $25 \mu \mathrm{g} / \mathrm{ml}$ ). Strains were subcultured $1 / 50$ into fresh antibiotic-free medium and grown at $37{ }^{\circ} \mathrm{C}$ with shaking $(200 \mathrm{rpm})$ to an $\mathrm{OD}_{600}$ of 0.5 . The cells were harvested by centrifugation, and RNA purified using Trizol reagent (Gibco/BRL) as specified by the manufacturer. RNA was DNase treated using the TURBO DNA-free kit (Ambion), followed by processing with a QIAGEN RNeasy kit clean-up with on-column DNase digestion as per the manufacturer's instructions.

\section{High-throughput RNA sequencing}

Double-stranded cDNA synthesis and high-throughput RNA-seq were performed as described previously [53]. For each strain three biological replicates were sequenced. Trimmed sequence reads were aligned to the B. pseudomallei K96423 genome sequence using SHRiMP [54] and normalised read counts were compared using voom and limma as described previously [53]. For each replicate sample, between 6.4 million and 14.0 million sequence reads were mapped uniquely to the K96423 genome sequence. The RNA-seq data is available at the NCBI Gene Expression Omnibus; accession number GSE77970. Differentially expressed genes were identified as those with a greater than 2-fold change in expression $\left(1.0 \log _{2}\right)$ across all replicates at a false discovery rate (FDR) of $<0.01$.

\section{Swarming motility assays}

Swarming agar plates were prepared fresh on the day of the assay using the modified protocol of Tunpiboonsak et al. [55]. Briefly, plates were prepared using $0.5 \% \mathrm{w} / v$ agar-agar (Merck), $8 \mathrm{~g} / \mathrm{L}$ nutrient broth No.2 (Oxoid) 
and $5 \mathrm{~g} / \mathrm{L} \mathrm{D}(+)$ - glucose (dextrose) (May and Baker) and dried carefully to give constant moisture content. Overnight cultures of B. pseudomallei parent strain K96243 and mutant strains were subcultured 1/50 into fresh medium with appropriate antibiotics (no selection for parent strain, $25 \mu \mathrm{g} / \mathrm{ml}$ tetracycline for all mutants and complemented mutants) and grown at $37^{\circ} \mathrm{C}$ with shaking $(200 \mathrm{rpm})$ to late exponential phase $\left(\mathrm{OD}_{600}\right.$ of $\left.\sim 2.5\right)$. A $5 \mu \mathrm{l}$ volume of each culture was spotted onto the centre of a swarming agar plate which was then incubated at $37{ }^{\circ} \mathrm{C}$ for $18 \mathrm{~h}$ in the dark. The diameter of the swarming population was then measured. Statistical analysis of swarming distance was determined by Student's t-test with a $P$-value of $<0.05$ considered significant.

\section{Ethics approval and consent to participate}

All animal experiments were carried out in accordance with the provisions of the "Prevention of Cruelty to Animal Act, 1986", the "Australian Code of Practice for the Care and Use of Animals for Scientific Purposes 7th edition, 2004" and the Monash University Animal Welfare Committee Guidelines and Policies. The protocol was approved by the Monash Animal Research Platform (MARP)-2 Animal Ethics Committee (AEC) of Monash University (AEC number MARP/2011/067).

\section{Consent for publication \\ Not applicable.}

\section{Availability of data and materials}

The RNA-seq data is available at the NCBI Gene Expression Omnibus; accession number GSE77970.

\section{Abbreviations}

2YT: yeast-tryptone medium; AEC: Animal Ethics Committee; FDR: false discovery rate; HAMP: Histidine kinases, Adenyl cyclases, Methyl-accepting proteins and Phosphatases; HATPase_c: Histidine kinase-like ATPase, Cterminal domain; HisKA: histidine kinase A domain; i.n.: intranasal; i.p.: intraperitoneal; LB: lysogeny broth; MARP: Monash Animal Research Platform; MCPs: methyl-accepting chemotaxis proteins; $\mathrm{OD}_{600}$ : optical density at $600 \mathrm{~nm}$; PBS: phosphate-buffered saline $\mathrm{pH}=7.2$; RNA-seq: RNA sequencing; RND: resistance-nodulation-division; RR: response regulator; SK: sensor kinase; T6SS-1: type VI secretion system cluster 1; T6SS-2: type 6 secretion system cluster 2; TCSTS: two-component signal transduction system; TISS3: type III secretion system locus 3.

\section{Competing interests}

The authors declare that they have no competing interests.

\section{Authors' contributions}

NLA, EA, DDL, SW, AD, BA, PT and PA performed the experiments. PH, DDL, EA, $\mathrm{NLA}, \mathrm{MH}, \mathrm{JB}$ performed statistical and bioinformatic analysis on the RNA-seq transcriptomic data. EA, NLA, BA, RD, MH and JB wrote and edited the manuscript. NLA, EA, BG, RD, MP, BA, MH and JB supervised the study. All authors read and approved the final manuscript

\section{Acknowledgements}

We thank Carla Osinski for excellent technical assistance and Alicia Shu-Chin Lai for her considerable help with animal experiments.

\section{Funding}

This work was funded by the Australian Research Council (Australia), Australian Research Council Centre of Excellence in Structural and Functional Microbial Genomics Grant number CE0562063 and the National Health and Medical Research Council (Australia), Project Grant numbers 545855 and 1043667.

\section{Author details}

'Department of Microbiology, Monash University, 19 Innovation Walk, Clayton, Victoria 3800, Australia. ${ }^{2}$ Infection and Immunity Program, Monash Biomedicine Discovery Institute, Monash University, Victoria, Australia. ${ }^{3}$ Victorian Bioinformatics Platform, Monash University, Victoria, Australia. ${ }^{4}$ Department of Biochemistry and Molecular Biology, Monash University, Victoria, Australia. ${ }^{5}$ Department of Microbiology and Immunology, James Cook University, Townsville, Queensland, Australia. ${ }^{6}$ Core Biotechnology Services, University of Leicester, Leicester LE1 9HN, UK. ${ }^{7}$ Department of Molecular Microbiology, Washington University School of Medicine, St. Louis, MO, USA. ${ }^{8}$ Faculty of Dentistry, National University of Singapore, Singapore, Singapore.

Received: 26 November 2015 Accepted: 26 April 2016

Published online: 04 May 2016

\section{References}

1. Currie BJ, Ward L, Cheng AC. The epidemiology and clinical spectrum of melioidosis: 540 cases from the 20 year Darwin prospective study. PLoS Negl Trop Dis. 2010;4, e900.

2. Limmathurotsakul D, Wongratanacheewin S, Teerawattanasook N, Wongsuvan G, Chaisuksant S, Chetchotisakd P, et al. Increasing incidence of human melioidosis in Northeast Thailand. Am J Trop Med Hyg. 2010;82:1113-7.

3. Stone R. Infectious disease. Racing to defuse a bacterial time bomb. Science. 2007:317:1022-4.

4. Douglas MW, Lum G, Roy J, Fisher DA, Anstey NM, Currie BJ. Epidemiology of community-acquired and nosocomial bloodstream infections in tropical Australia: a 12-month prospective study. Trop Med Int Health. 2004;9:795-804.

5. Chaowagul W, White NJ, Dance DA, Wattanagoon Y, Naigowit P, Davis TM, Looareesuwan S, Pitakwatchara N. Melioidosis: a major cause of communityacquired septicemia in northeastern Thailand. J Infect Dis. 1989;159:890-9.

6. Livermore DM, Chau PY, Wong Al, Leung YK. beta-Lactamase of Pseudomonas pseudomallei and its contribution to antibiotic resistance. J Antimicrob Chemother. 1987;20:313-21.

7. Moore RA, DeShazer D, Reckseidler S, Weissman A, Woods DE. Efflux-mediated aminoglycoside and macrolide resistance in Burkholderia pseudomallei. Antimicrob Agents Chemother. 1999;43:465-70.

8. Schweizer HP. Efflux as a mechanism of resistance to antimicrobials in Pseudomonas aeruginosa and related bacteria: unanswered questions. Genet Mol Res. 2003;2:48-62.

9. Hoch JA. Two-component and phosphorelay signal transduction. Curr Opin Microbiol. 2000;3:165-70.

10. Stock AM, Robinson VL, Goudreau PN. Two-component signal transduction. Annu Rev Biochem. 2000;69:183-215.

11. Krell T, Lacal J, Busch A, Silva-Jimenez H, Guazzaroni ME, Ramos JL. Bacterial sensor kinases: diversity in the recognition of environmental signals. Annu Rev Microbiol. 2010;64:539-59.

12. Gao R, Stock AM. Biological insights from structures of two-component proteins. Annu Rev Microbiol. 2009;63:133-54.

13. Gotoh Y, Eguchi Y, Watanabe T, Okamoto S, Doi A, Utsumi R. Two-component signal transduction as potential drug targets in pathogenic bacteria. Curr Opin Microbiol. 2010;13:232-9.

14. Cegelski L, Marshall GR, Eldridge GR, Hultgren SJ. The biology and future prospects of antivirulence therapies. Nat Rev Microbiol. 2008;6:17-27.

15. Holden MT, Titball RW, Peacock SJ, Cerdeno-Tarraga AM, Atkins T, Crossman LC, Pitt T, Churcher C, Mungall K, Bentley SD, et al. Genomic plasticity of the causative agent of melioidosis, Burkholderia pseudomallei. Proc Natl Acad Sci U S A. 2004:101:14240-5.

16. Wiersinga WJ, de Vos AF, de Beer R, Wieland CW, Roelofs JJ, Woods DE, van der Poll T. Inflammation patterns induced by different Burkholderia species in mice. Cell Microbiol. 2008;10:81-7.

17. Jones AL, DeShazer D, Woods DE Identification and characterization of a two-component regulatory system involved in invasion of eukaryotic cells 
and heavy-metal resistance in Burkholderia pseudomallei. Infect Immun. 1997;65:4972-7.

18. Mahfouz ME, Grayson TH, Dance DA, Gilpin ML. Characterization of the mrgRS locus of the opportunistic pathogen Burkholderia pseudomallei: temperature regulates the expression of a two-component signal transduction system. BMC Microbiol. 2006;6:70.

19. Chen Y, Wong J, Sun GW, Liu Y, Tan GY, Gan YH. Regulation of type VI secretion system during Burkholderia pseudomallei infection. Infect Immun. 2011;79:3064-73.

20. Tuanyok A, Tom M, Dunbar J, Woods DE. Genome-wide expression analysis of Burkholderia pseudomallei infection in a hamster model of acute melioidosis. Infect Immun. 2006;74:5465-76.

21. Cuccui J, Easton A, Chu KK, Bancroft GJ, Oyston PC, Titball RW, Wren BW. Development of signature-tagged mutagenesis in Burkholderia pseudomallei to identify genes important in survival and pathogenesis. Infect Immun. 2007;75:1186-95.

22. Atkins T, Prior R, Mack K, Russell P, Nelson M, Prior J, Ellis J, Oyston PC, Dougan G, Titball RW. Characterisation of an acapsular mutant of Burkholderia pseudomallei identified by signature tagged mutagenesis. J Med Microbiol. 2002;51:539-47.

23. Chistoserdova L, Chen SW, Lapidus A, Lidstrom ME. Methylotrophy in Methylobacterium extorquens AM1 from a genomic point of view. J Bacteriol. 2003;185:2980-7

24. Chan YY, Tan TM, Ong YM, Chua KL. BpeAB-OprB, a multidrug efflux pump in Burkholderia pseudomallei. Antimicrob Agents Chemother. 2004;48:1128-35.

25. Tribuddharat C, Moore RA, Baker P, Woods DE. Burkholderia pseudomalle class a beta-lactamase mutations that confer selective resistance against ceftazidime or clavulanic acid inhibition. Antimicrob Agents Chemother. 2003;47:2082-7.

26. Rholl DA, Papp-Wallace KM, Tomaras AP, Vasil ML, Bonomo RA, Schweizer HP. Molecular Investigations of PenA-mediated beta-lactam Resistance in Burkholderia pseudomallei. Front Microbiol. 2011;2:139.

27. Harland DN, Dassa E, Titball RW, Brown KA, Atkins HS. ATP-binding cassette systems in Burkholderia pseudomallei and Burkholderia mallei. BMC Genomics. 2007:8:83.

28. Burtnick MN, Brett PJ, Harding SV, Ngugi SA, Ribot WJ, Chantratita N, Scorpio A, Milne TS, Dean RE, Fritz DL, et al. The cluster 1 type VI secretion system is a major virulence determinant in Burkholderia pseudomallei. Infect Immun. 2011;79:1512-25.

29. Seyedsayamdost MR. High-throughput platform for the discovery of elicitors of silent bacterial gene clusters. Proc Natl Acad Sci U S A. 2014;111:7266-71.

30. Truong TT, Seyedsayamdost M, Greenberg EP, Chandler JR. A Burkholderia thailandensis acyl-homoserine lactone-independent orphan luxr homolog that activates production of the cytotoxin malleilactone. J Bacteriol. 2015; 197:3456-62.

31. Sun GW, Chen YH, Liu YC, Tan GYG, Ong C, Tan P, Gan YH. Identification of a regulatory cascade controlling Type III Secretion System 3 gene expression in Burkholderia pseudomallei. Mol Microbiol. 2010;76:677-89.

32. Chen YH, Schroder I, French CT, Jaroszewicz A, Yee XJ, Teh BE, Toesca IJ, Miller JF, Gan YH. Characterization and analysis of the Burkholderia pseudomallei BsaN virulence regulon. BMC Microbiol. 2014;14:206.

33. Hengge R. Principles of c-di-GMP signalling in bacteria. Nat Rev Microbiol. 2009; 7:263-73.

34. Yamamoto K, Hirao K, Oshima T, Aiba H, Utsumi R, Ishihama A. Functional characterization in vitro of all two-component signal transduction systems from Escherichia coli. J Biol Chem. 2005;280:1448-56.

35. Amemura M, Makino K, Shinagawa H, Nakata A. Cross talk to the phosphate regulon of Escherichia coli by PhoM protein: PhoM is a histidine protein kinase and catalyzes phosphorylation of PhoB and PhoM-open reading frame 2. J Bacteriol. 1990;172:6300-7.

36. Guckes KR, Kostakioti M, Breland EJ, Gu AP, Shaffer CL, Martinez 3rd CR, Hultgren SJ, Hadjifrangiskou M. Strong cross-system interactions drive the activation of the QseB response regulator in the absence of its cognate sensor. Proc Natl Acad Sci U S A. 2013;110:16592-7.

37. Kostakioti M, Hadjifrangiskou M, Pinkner JS, Hultgren SJ. QseC-mediated dephosphorylation of QseB is required for expression of genes associated with virulence in uropathogenic Escherichia coli. Mol Microbiol. 2009;73:1020-31.
38. Oshima T, Aiba H, Masuda Y, Kanaya S, Sugiura M, Wanner BL, Mori H, Mizuno T. Transcriptome analysis of all two-component regulatory system mutants of Escherichia coli K-12. Mol Microbiol. 2002;46:281-91.

39. Lee HS, Gu F, Ching SM, Lam Y, Chua KL. CdpA is a Burkholderia pseudomallei cyclic di-GMP phosphodiesterase involved in autoaggregation, flagellum synthesis, motility, biofilm formation, cell invasion, and cytotoxicity. Infect Immun. 2010;78:1832-40.

40. Sourjik V, Wingreen NS. Responding to chemical gradients: bacterial chemotaxis. Curr Opin Cell Biol. 2012;24:262-8.

41. Roberts MA, Papachristodoulou A, Armitage JP. Adaptation and control circuits in bacterial chemotaxis. Biochem Soc Trans. 2010;38:1265-9.

42. Reader RW, Tso WW, Springer MS, Goy MF, Adler J. Pleiotropic aspartate taxis and serine taxis mutants of Escherichia coli. J Gen Microbiol. 1979;111:363-74.

43. Yao J, Allen C. Chemotaxis is required for virulence and competitive fitness of the bacterial wilt pathogen Ralstonia solanacearum. J Bacteriol. 2006;188:3697-708.

44. DeShazer D, Brett PJ, Carlyon R, Woods DE. Mutagenesis of Burkholderia pseudomallei with Tn5-OT182: isolation of motility mutants and molecular characterization of the flagellin structural gene. J Bacteriol. 1997;179:2116-25.

45. Wikraiphat C, Charoensap J, Utaisincharoen P, Wongratanacheewin S, Taweechaisupapong S, Woods DE, Bolscher JG, Sirisinha S. Comparative in vivo and in vitro analyses of putative virulence factors of Burkholderia pseudomallei using lipopolysaccharide, capsule and flagellin mutants. FEMS Immunol Med Microbiol. 2009;56:253-9.

46. Chua KL, Chan YY, Gan YH. Flagella are virulence determinants of Burkholderia pseudomallei. Infect Immun. 2003;71:1622-9.

47. Milton DL, OToole R, Horstedt P, Wolf-Watz H. Flagellin A is essential for the virulence of Vibrio anguillarum. J Bacteriol. 1996;178:1310-9.

48. Hunger M, Schmucker R, Kishan V, Hillen W. Analysis and nucleotide sequence of an origin of DNA replication in Acinetobacter calcoaceticus and its use for Escherichia coli shuttle plasmids. Gene. 1990;87:45-51.

49. Szpirer CY, Faelen M, Couturier M. Mobilization function of the pBHR1 plasmid, a derivative of the broad-host-range plasmid pBBR1. J Bacteriol. 2001;183:2101-10

50. Harper M, Boyce JD, Wilkie IW, Adler B. Signature-tagged mutagenesis of Pasteurella multocida identifies mutants displaying differential virulence characteristics in mice and chickens. Infect Immun. 2003;71:5440-6.

51. Leakey AK, Ulett GC, Hirst RG. BALB/C and C57BI/6 mice infected with virulent Burkholderia pseudomallei provide contrasting animal models for the acute and chronic forms of human melioidosis. Microb Pathog. 1998;24:269-75

52. Reed $\sqcup$, Muench $\mathrm{H}$. A simple method of estimating fifty percent endpoints. Amer J Hyg. 1938;27:493-7.

53. Henry R, Crane B, Powell D, Deveson Lucas D, Li Z, Aranda J, Harrison P, Nation RL, Adler B, Harper M, et al. The transcriptomic response of Acinetobacter baumannii to colistin and doripenem alone and in combination in an in vitro pharmacokinetics/pharmacodynamics model. J Antimicrob Chemother. 2015:70:1303-13.

54. Rumble SM, Lacroute P, Dalca AV, Fiume M, Sidow A, Brudno M. SHRiMP: accurate mapping of short color-space reads. PLoS Comput Biol. 2009;5, e1000386.

55. Tunpiboonsak S, Mongkolrob R, Kitudomsub K, Thanwatanaying P, Kiettipirodom W, Tungboontina Y, et al. Role of a Burkholderia pseudomallei polyphosphate kinase in an oxidative stress response, motilities, and biofilm formation. J Microbiol. 2010;48:63-70. 